University of Rhode Island

DigitalCommons@URI

Open Access Dissertations

2013

\title{
Asleep Behind the Wheel: Experiences of Night Shift Nurses on the Commute Home
}

Shirley A. Sargent

University of Rhode Island, ssargent81@gmail.com

Follow this and additional works at: https://digitalcommons.uri.edu/oa_diss

\section{Recommended Citation}

Sargent, Shirley A., "Asleep Behind the Wheel: Experiences of Night Shift Nurses on the Commute Home" (2013). Open Access Dissertations. Paper 35.

https://digitalcommons.uri.edu/oa_diss/35

This Dissertation is brought to you for free and open access by DigitalCommons@URI. It has been accepted for inclusion in Open Access Dissertations by an authorized administrator of DigitalCommons@URI. For more information, please contact digitalcommons-group@uri.edu. 
ASLEEP BEHIND THE WHEEL: EXPERIENCES OF

NIGHT SHIFT NURSES ON THE COMMUTE HOME

BY

SHIRLEY A. SARGENT

A DISSERTATION SUBMITTED IN PARTIAL FULFILLMENT OF THE REQUIREMENTS FOR THE DEGREE OF DOCTOR OF PHILOSOPHY

IN

NURSING

UNIVERSITY OF RHODE ISLAND

2013 


\section{DISSERTATION}

$\mathrm{OF}$

\section{SHIRLEY SARGENT}

\section{APPROVED:}

Dissertation Committee:

Major Professor $\quad$ Dr. Marlene Dufault

Dr. Ginette Ferszt

Dr. Laura Beauvais

Nasser H. Zawia DEAN OF THE GRADUATE SCHOOL 


\begin{abstract}
Aim: The aim of this study was to obtain descriptions of nurses' perceptions and experiences of falling asleep behind the wheel on the drive home after a worked night shift.
\end{abstract}

Background: While the evidence suggests that the problem of drowsy driving and fall asleep driving is a strong contributor to vehicular accidents, little is known about nursing perceptions of the issue.

Methods: The design of the study is qualitative and descriptive. Face-to-face interviews were conducted with 12 registered nurses who had experienced falling asleep behind the wheel on the drive home from work after a worked night shift. The interviews were transcribed verbatim and analyzed using content analysis.

Results: The eight themes which emerged from the data evolved from factors identified by the participants during the interviews. They were: (1.) night shifts better for new grads, (2.) auto-pilot, (3.) struggling to stay awake, (4.) it’s scary, (5.) just need to get home, (6.) not a night person, (7.) feeling awful, and (8.) don’t know how to fix it.

Conclusion: This study strongly suggests the need for additional research. Because we know that drowsy and fall asleep driving after a worked night shift is a ubiquitous phenomenon among night nurses, the need to develop interventions to mitigate the risks of the phenomenon was confirmed. The findings emphasize the importance of open dialogue and heightened awareness of the dangers faced by the nurses when they have finished their shift and are driving home. Understanding the context of nurses' experiences with falling asleep behind the wheel may elicit stronger communications 
between nurses and their nursing leaders. Targeted education on sleep hygiene, drowsy driving, and fall asleep driving for nurses, nursing leaders, and hospital administrators may serve to open the dialogue. Negative physiologic and psychological influences of night shift centered around poor quality and quantity of sleep. These negative influences were consistently presented by all participants. The nurses' beliefs that they are physically unable to adapt to shiftwork warrants further research into screening for physiological and psychological ability to engage in shiftwork. Further studies are needed to explore the efficacy of restorative napping, and other interventions to prevent drowsy and fall asleep driving. Many participants expressed the fact that they had little to no choice but to work the night shift as new graduates. We need to closely examine why the newest members of the nursing profession are placed on the shift with the least amount of resources. The phenomenon of fall asleep driving after a worked night shift environment in nursing is poorly understood. The goal of this qualitative descriptive study was to elicit a description of the experience of night shift nurses with the goal of obtaining information that would serve to find ways to eliminate the occurrence of drowsy/fall asleep driving in nurse shiftworkers. Nursing and hospital administrators may be able to utilize the information gleaned from this study to optimize the nurse scheduling, implement evidence based interventions, and subsequently, keep the nurses safe. 


\section{ACKNOWLEDGMENTS}

This dissertation could not have been written without the friendship and support that I received in the University of Rhode Island College of Nursing Doctoral program. It has been a long journey and completing this work is a high point in my life.

I wish to express my deepest gratitude to the chair of my dissertation committee, Dr. Marlene Dufault who always gave me excellent advice and counsel. Marlene has been a strong and supportive advisor to me throughout my doctoral school career. Marlene has been a role model to me since I worked with her as her Graduate Assistant. Marlene, you are a kind, intelligent, and wonderful person. I am blessed to know you. Without her guidance and persistent help, this dissertation would not have been possible.

Special thanks goes to Dr. Ginette Ferszt who was abundantly helpful, patient, and provided invaluable assistance, support, and guidance during this process. My deepest gratitude and thanks are also due to the members of my Dissertation Committee: Drs. Laura Beauvais, Diane Martins, and Jerry Cohen.

The author wishes to express her love and gratitude to her beloved family; for their understanding and endless love, through the duration of my studies. To my husband Jeff, thank you for caring and supporting me during this process. Thank you for all those long days on the weekends that you kept me company in the library. We will enjoy our weekends again! I could not have done it without you. 
To my three children Briana, Deirdre, and Ryan, your support, encouragement, and constant love have sustained me. You are my world. Mom, Dad, and Bob--thank you for always being so proud of me and giving me your undying support.

Peter, I thank you for your company during late nights of typing. 


\section{DEDICATION}

This dissertation is dedicated to my husband Jeff, who has been my emotional anchor through not only the years of doctoral study, but in life. 
TABLE OF CONTENTS

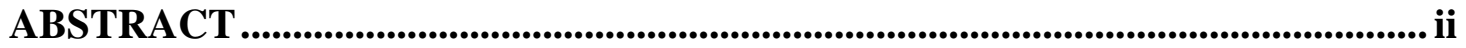

ACKNOWLEDGMENTS ..............................................................................................iv

TABLE OF CONTENTS..................................................................................................vii

LIST OF TABLES ....................................................................................................ii

LIST OF FIGURES ...................................................................................................

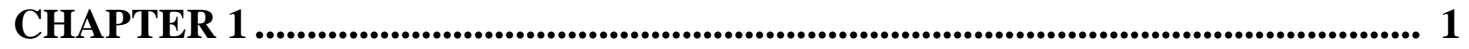

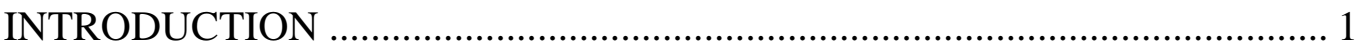

CHAPTER 2 ................................................................................................................. .6

REVIEW OF LITERATURE ............................................................... .6

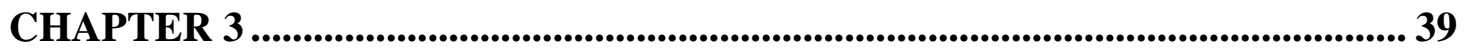

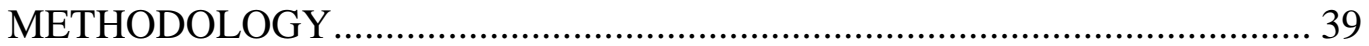

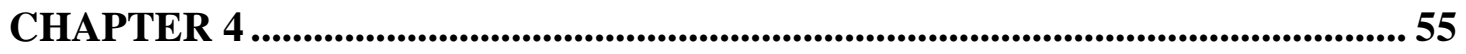

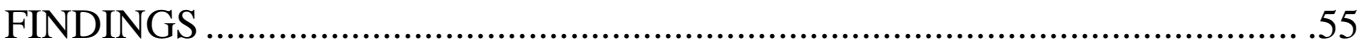

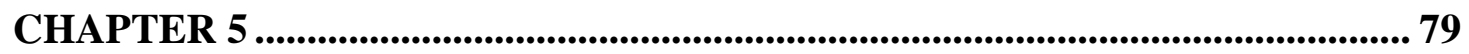

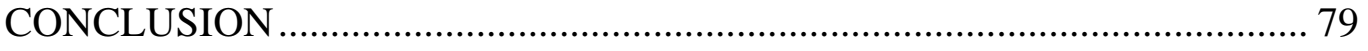

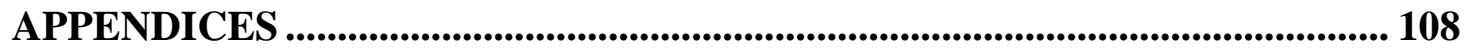

BIBLIOGRAPHY …................................................................................................... 114 


\section{LIST OF TABLES}

TABLE

PAGE

Table 1. Examples of meaning units, condensed meaning units, and codes............... 50

Table 2. Frequency and Percentage Distribution of Registered Nurses...................... 55

Table 3. Qualitative Description-Major Tenets ..................................................... 91

Table 4. Characteristics of the Responsive Interviewing Model .............................. 92

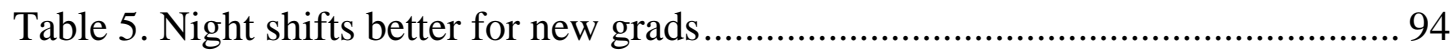

Table 6. Struggling to stay awake.........................................96

Table 7. It's Scary .......................................................97

Table 8. Just need to get home............................................................99

Table 9. Not a Night Person............................................... 101

Table 10. Feeling Awful..................................................103

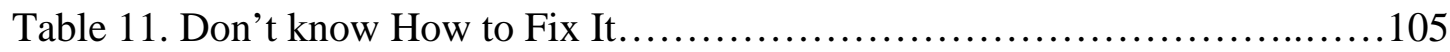




\section{LIST OF FIGURES}

Figure 1. Inductive and deductive Content Analysis Process................................ 107 


\section{CHAPTER 1}

\section{INTRODUCTION}

\section{Justification for and Significance of the Study}

Nurses who work the night shift must adjust to being awake at a time when their natural circadian rhythms are prompting them to sleep. Their work environment is focused on patient comfort in that the lights are dimmed, voices are hushed, patients are sleeping, and the cafeteria is closed. At the end of their shift, they step into daylight and must remain alert for the drive home.

Nursing will always be a 24 hour, 7 day a week profession. Eliminating the night shift is not an option. Those who drive when they are drowsy, place themselves and others in immediate danger. When sleepy drivers get behind the wheel, they risk their own lives and the lives of others.

Drowsiness is the last step before falling asleep. According to Dr. Dement, Division Chief of the Stanford University Division of Sleep, "The crucial event that occurs as we fall asleep is an abrupt shut down of the neural processes that allow us to perceive the world around us. At one moment we are awake, and can see and hear. A fraction of a second later we are asleep, and we are completely blind and completely deaf” (Dement, 1997, para.20). Although the vast majority of drivers recognize the serious threat of drowsy driving, a 'do as I say, not as I do' attitude exists when getting behind the wheel. Drowsy driving is no different in that it kills just as drunk, drugged and distracted driving does. "Drivers have a tendency to underestimate the impact being tired has on their driving ability, which puts themselves and others at risk." (AAA Foundation for Traffic Safety, 2004, para.2). These drivers are involved in one 
of every six deadly crashes and one in eight crashes resulting in serious injury, (AAA Foundation, 2010; AAA Foundation for Traffic Safety., 2004). The 2012 Safety culture index found that $96 \%$ of drivers find it unacceptable to drive when they are so sleepy that it is difficult to keep their eyes open (AAA Foundation, 2013). While few if any nurses would disagree with the statements above, many who work the night shift routinely get into their cars every morning after a worked night shift and drive drowsy placing their own lives as well as the lives of others at risk.

Thirty two years ago I had a fall asleep driving incident that significantly shaped my attitude towards driving after working the night shift. As a new graduate nurse, I was assigned to the night shift. At my new hospital of employment, new graduates were automatically assigned to the night shift. I began my new position with a six week orientation to the unit on the day shift followed by a one week orientation to the night shift.

I quickly acclimated to the night routine and the work of a Registered Nurse (RN). I enjoyed my new career as well as working with my new colleagues. While I was gaining confidence in my abilities and strengthening my level of competency, I began to sense a decline in both my personal and physical sense of well-being. I was always tired. I struggled to keep my eyes opened and stay awake during the drive home after work. I fell asleep immediately upon my return home and slept soundly for approximately eight hours. Despite this, I never felt fully awake. I began to fall asleep in inappropriate situations; waiting for an appointment, waiting to pick up my dry cleaning, sitting in a conference, and attending an in-service or staff meeting. I felt a sense of shame and embarrassment after falling asleep in front of others. I became 
depressed and isolative. I gained weight from a cycle of eating high glucose foods and caffeinated soft drinks in an effort to stay awake.

As part of a new graduate nurse cohort we met on a regular basis. During these meetings we discussed our experiences as new RNs. I was secretive and did not share my issue of falling asleep behind the wheel with the group. I saw it as a personal weakness and was concerned that it would reflect poorly on me as a professional.

After approximately six months of working the night shift I was driving home after work one morning. My commute was only twenty minutes in length. I felt drowsy, but no more so than usual. I awoke and found that my passenger window been broken by a police officer. I had fallen asleep behind the wheel and hit two parked cars. I sustained multiple lacerations as well as a severe concussion. The cars were parked near a busy sidewalk. Fortunately, there were no pedestrian injuries.

After the accident, for a period of approximately eight months, I suffered recurrent nightmares and anxiety about "what could have" happened? What if the parked cars had not shielded the busy sidewalk? What if I had harmed a pedestrian or another driver? I felt great shame, self loathing, and horror when I thought of the accident. Despite all of this, I continued to work the night shift. As a new graduate nurse, working the day shift was not an option as this shift was reserved for the more “senior” nurses. I subsequently had multiple near misses and episodes of "nodding off" at the wheel.

Sadly, many nurses who work the night shift can easily relate to this personal story. I was able to go to the day shift by taking a position in nursing administration. My transition to nursing administration was made possible in part by my length of 
experience as a staff nurse, which included the requisite years of shift work. Leaving the bedside care that I greatly enjoyed seemed a small price to pay for saving my life and/or someone else's.

I thrived on the day shift. I enjoyed my work in nursing administration as the Nurse Manager of a busy intensive care unit and put those difficult years of working the night shift behind me. I was on the unit one day when I received a call that we would be getting an admission from the Operating Room. The patient was a young woman, a nurse's aide who had worked the night shift the night immediately prior. She had left work, picked up her young son and was driving him to his pre-school. She fell asleep and drove through a busy intersection. Her son died shortly after the accident. She had multiple injuries but would survive. What bed did I want to assign her to? , asked the operating room clerk. I caught my breath and assigned the room number. I ran into my office and had great difficulty catching my breath. I sobbed. That could have been me. The feeling of terror and sadness that passed through me was overwhelming.

According to the New York State Partnership Against Drowsy Driving (NYPDD), a task force formed in 1994 to reduce drowsy driving, fatigue-related crashes tend to be single-vehicle crashes in which a car or truck leaves the roadway and then turns over or hits a fixed object. They estimated that between 40 and 60 percent of these "run-off-road" crashes are due to driver fatigue, drowsiness or inattention. Run-off-road crashes constitute a serious highway safety problem, accounting for one-third of all traffic fatalities nationally and two-thirds of fatalities in rural areas. While police officers may implicate fatigue in crashes, there is rarely 
sufficient evidence to prove sleep as a causal issue. The evidence is usually circumstantial using identifying markers such as the absence of skid marks, off the road single vehicle accidents and a lack of poor road conditions.

The significance of the issue of drowsy driving and fall-asleep driving cannot be understated. As I began to discuss this issue with my staff and colleagues, I learned that many of night nurses dealt with this issue on a regular basis. Countless nurses had stories of falling asleep on the commute home when they worked the night shift. I identified the need for heightened awareness of the issue of falling asleep at the wheel after a worked night shift.

Only by speaking candidly and openly about this issue, can we begin to work towards safe solutions that will keep nurses and the public safe. We cannot wait until the public sanctions us to police ourselves; we need to deal with this problem in a professional and ethically responsible manner. 


\section{CHAPTER 2}

\section{REVIEW OF LITERATURE}

"Sleep is the golden chain that ties health and our bodies together" - Thomas Dekker - The Guls Horne Book, 1609

The review of the literature for this dissertation was based on key terms taken from the question, "What is the experience of nurses falling asleep behind the wheel on the drive home after a worked night shift?” The goal of this review was to determine the state of the science regarding this topic and identify the existence of gaps in the literature.

\section{Literature Search Method}

Searches were performed in the databases of PubMed, CINAHL and Google Scholar and Dissertation Abstracts. Based on the research question, the key primary search terms were 1.) night nurses, 2.) night shift nurses, 3.) asleep behind the wheel, and 4.) drowsy driving. The terms were searched independently and in inclusive combinations.

\section{Shiftwork}

The term "shift work” holds different meaning to different people. Many researchers define shift work as working outside of the standard daylight hours of 8am-6pm. Most discussions involving nurses consider shift work to be hours worked between 7pm and 7am. The length of a standard nursing shift can vary between 8 and 12 hours. For the purpose of this dissertation, “shift work” refers to the hours of overnight work that begin either at 7pm or 11pm until 7am. "Rotational shift work" refers to a work schedule that alternates between the day shift and the night shift in the 
case of 12 hour shifts, and the day shift and the evening shift or night shift in the case of 8 hours shifts. A night shift is either a group of workers who work during the night, or the period in which they work. For the purpose of this dissertation, night shift is the time of work.

Until the invention of electricity, shift work was mainly limited to soldiers and sailors. With the advent of electric lighting, global travel, customer demands, the internet, and increasing economic and social demands, we have evolved into a 24 hour society. We are able to do the same work during the night hours as we can during the daytime. The history of shift work in America can be traced back to the industrial revolution in the 18th and 19th centuries. Factory owners realized that keeping their machinery running 24 hours a day could maximize production.

Care of patients in the hospital is a 24 hour, 7 days a week occupation. Natural human circadian cycles are no longer considered a time constraint. Technology in healthcare as well as the advanced illness of the hospitalized patient has led to a 24 hour health care system requiring nurses to work during the night hours. The level of performance and productivity expected of nurse shift workers is no different than that of their day counterparts. For most nurses, entry into the profession is their initial experience with shiftwork. "To further compound this issue, most healthcare professionals, including nurses, typically receive little or no formal education about normal sleep and circadian rhythms, or the essential role of sleep in maintaining adequate health and performance either during or after their training” (Owens, 2007, p.92). 
The conveniences of maintaining a 24-7 society are not without cost. The loss of sleep incurred by working the night shift has its consequences in the areas of physical health, psychological health, social life, family life, work performance, and the economy. Individuals involved in shift work and rotating shifts rarely get enough sleep. In a study by Czeisler et al. (1980), it was determined that night shift workers obtain 1 to 4 hours less sleep than normal when they are working nights. While the amount of sleep required by adults varies, the effect of insufficient sleep is well documented. Intuitively, the leading cause of drowsy driving and fall asleep car accidents is sleep loss (National Highway Traffic Safety Administration \& National Center on Sleep Disorders Research, 1999).

Interest in the effects of shift work on people developed because many experts have blamed shift work for the "human error" connected with medical errors, nuclear power plant incidents, airplane crashes, and other catastrophic accidents. The key accident that caused the 1979 meltdown at the Three Mile Island nuclear generator in Pennsylvania occurred at 4am, and was made by operators working the night shift. The accident at the Chernobyl nuclear power plant in the Ukraine is the worst nuclear disaster in history. The accident started at 1:26 am on April, 26 1986. The cause of the disaster has been partially attributed to human error caused by confusion and fatigue.

According to Flight Duty Times (2013), in 2011 an airplane flying from Stockholm to Copenhagen was pilotless for a while after the co-pilot left the cockpit for a short time and the captain fell fast asleep. On October 22, 2009, the pilots of a Northwest Airlines airplane flew past their destination airport by about 150 miles and 
did not respond to any radio contact for over an hour. The cockpit was finally notified of the error by a flight attendant.

A pilot study of 23 Australian nurses found that they experienced sleepiness and related physical symptoms both at work and during their trip home. "Further, a measurable number of errors occur of various types and severity. "Less sleep may lead to the increased likelihood of making an error, and importantly, the decreased likelihood of catching someone else's error “(Dorrian et al., 2008, p. 92).

Approximately $30 \%$ of the nursing population is involved in shiftwork (Hughes \& Stone, 2004). Many nurses find that shift work disrupts their family and personal life and leads to health problems including chronic fatigue, depression and gastrointestinal disorders. Nurses who do work the night shift must function optimally on a schedule that is not "natural.” The imbalance in homeostasis caused by shift work can produce a wide range of effects on physiological systems. Epidemiological studies report decreased health in shiftworkers, including increased cardiovascular complaints and reproductive dysfunctions in night workers.

\section{What is Sleep?}

The effects of sleep on our physical and mental health are the topic of many research studies. An understanding of the mechanism of sleep is critical to this research. Neurotransmitters control whether we are asleep or awake by acting on different neurons in the brain. Neurons in the brainstem produce the neurotransmitters seratonin and norepinephrine. These neurotransmitters keep some parts of the brain awake while others sleep. Wakefulness includes Gamma, High Beta, Mid Beta, Beta 
Sensory Motor Rhythm, Alpha, and Theta brain waves. Our composite brain waves are made up of many of these brain waves all at the same time (Walcutt, 2009). There are five stages of sleep:(National Institutes of Neurological Disorders and Stroke, 2007).

stage one

As we prepare to sleep, we move through Alpha and Theta. During the Alpha stage, we are restful and may experience a feeling of falling or muscle twitches. These are known as hypnogogic hallucinations. As we enter Theta, we are in light sleep. Stage 1 lasts approximately 5-10 minutes. In this stage, the eyes are closed. The person can be easily awakened. When awakened from Stage 1, people often feel that they have not slept (Walcutt, 2009).

stage two

The second stage of sleep lasts about 20 minutes. Our brain begins to produce very short periods of rapid, rhythmic brain wave activity known as Sleep Spindles (Walcutt, 2009). Body temperature begins dropping and heart rate starts slowing down.

stage three

Deep, slow brain waves known as Delta Waves begin to emerge during this stage. It is a transitional period between light sleep and a very deep sleep (National Institutes of Neurological Disorders and Stroke, 2007).

\section{stage four}

This is sometimes referred to as Delta Sleep because of the delta waves that occur during this time. Stage Four is a deep sleep that lasts for about 30 minutes. 
Sleepwalking and bed-wetting typically happen at the end of Stage Four sleep

(Walcutt, 2009).

stage five:

\section{rapid eye movement (REM)}

Most dreaming occurs during Stage Five, known as Rapid Eye Movement (REM).

REM sleep is characterized by eye movement, increased respiration rate and increased brain activity. REM sleep is also referred to as paradoxical sleep because, while the brain and other body systems become more active, the muscles become more relaxed, or paralyzed. Dreaming occurs because of increased brain activity, but voluntary muscles become paralyzed. Voluntary muscles are those that you need to move by choice, for example, your arms and legs. Involuntary muscles are those that include your heart and gut. They move on their own (Walcutt, 2009). This period of paralysis is a built-in protective measure to keep you from harming yourself. When you are paralyzed, you can't leap out of bed and run. This state protects us from actually running or other movement as we often may wish to do in our dreams (Walcutt, 2009).

\section{Sleep Cycles}

Sleep does not progress through all of these stages in sequence. We pass through five stages of sleep. These are stages 1, 2, 3, 4, and REM sleep. Sleep begins in Stage 1 and progresses into stages 2, 3, and 4. Then, after Stage 4 sleep, Stages 3, then 2 are repeated before going into REM sleep. Once REM is over, we usually return to Stage Two sleep. Sleep cycles through these stages approximately 4 or 5 times throughout the night. 
Typically, we enter REM approximately 90 minutes after falling asleep. The first cycle of REM often lasts only a short amount of time, but each cycle becomes longer. During a normal night sleep, a sleeper passes from the theta waves of stage 1 and 2, to the delta waves of stage 3 and 4 . The cycles progress in cycle from stage 1 to REM. We spend approximately 20\% of our time in REM, 50\% in Stage 2 and $30 \%$ in the other stages. A sleeper begins in stage 1 , moves down through the stages, to stage 4, then back up through the stages, with the exception that stage 1 is replaced by REM, then the sleeper goes back down through the stages again. One cycle, from stage 1 to REM takes approximately ninety minutes. This cycle is repeated throughout the night, with the length of REM periods increasing, and the length of delta sleep decreasing, until during the last few cycles there is no delta sleep.

When we only get short periods of sleep, we can't really get through the stages we need to remain healthy and rejuvenated. This is why we need long periods of sleep each night. REM can last up to an hour as our sleep progresses.

\section{Circadian Rhythm}

The body is programmed to sleep when it's dark and to be awake during 'light' hours. The use of electric lighting, alarm clocks, pharmacologic sleep aids and engagement in shiftwork wreak havoc on the process of sleep. Stress hormones attempt to mediate anything that alters this schedule, which causes many types of internal inflammation, fat metabolism, and other issues leading to cancer and heart disease. Sleep/wake patterns, hormone levels, and physiological processes such as core body temperature and heart rate are controlled by a daily biological clock (Gamble, 2011). Approximately one hundred psychological and physiological bodily 
functions oscillate between minimum and maximum values in a day long cycle. The circadian rhythm is critical in determining human sleeping patterns.

The term, “circadian” rhythm was coined by Dr. Franz Halberg in 1959. That daily biological clock, known as Circadian rhythm (Latin: $\operatorname{circa}=$ about, and dies $=\mathrm{a}$ day), is the human body's natural tendency to follow a 24 hour cycle. Circadian bodily rhythm is determined by the nucleus suprachiasmaticus (SCN) located in the hypothalamus. These rhythms are endogenously produced by an organism. Circadian rhythms are composed of repetitive oscillations having a frequency of one cycle approximately every 24 hours, and sustained in constant environmental conditions. Circadian disruption occurs as a result of misalignment in the timing of circadian rhythms in relation to either the external light-dark cycle or to each other (Rogers \& Dinges, 2002).

Our bodies naturally follow the circadian rhythms of wakefulness and sleepiness, with the desire to sleep strongest between midnight and 6 a.m., and between 2 p.m. and 4 p.m. When sleep/wake patterns are out of synchronization with the endogenous clock and/or the environment, such as during shift work, circadian misalignment can result. Circadian disruption, also known as chronodisruption, is a disturbance of the circadian organization of human physiology, endocrinology, metabolism, and behavior. The most basic principle underlying the circadian rhythm variation is readiness for action during daytime and rest at nighttime.

Circadian rhythms are largely driven by the internal body clock and synchronized to the external world by cues known as "zeitgebers.” The word “zeitgeber” was coined in 1954 by a German biologist named Jurgen Aschoff who 
studied circadian rhythms. Literally translated, "zeitgeber" means "time giver”. The zeitgeber cue influences the operations of the internal clock of an individual. Light is an example of a zeitgeber. Light, as an external cue leads many individuals to wake up with most people drawn to sleep between the hours of midnight and 6 AM (National Sleep Foundation, 2007). Interruptions in these cues can lead to functional difficulty and potential health problems. Since our bodies are programmed to relax after dark and be alert during the day, shiftwork forces the body to combat the natural time of rest. We are forcing the body to work counter to its natural cycle.

The basis for night shift chronodisruption is exposure to light at night. The pineal gland-secreted hormone melatonin is the "messenger of time" that transmits information about environmental light and darkness, obtained from ganglion cells in the retina, through the hypothalamus to all tissues of the body (Bara \& Arber, 2009). Melatonin is synthesized and secreted at night and acts as a signal for the length of day and night. Light suppresses melatonin secretion in a dose (or intensity) dependent manner. Normal, nocturnal night sleep occurs during the rising phase of melatonin secretion. Attempts to sleep during the declining phase of melatonin secretion, sleep can be shorter with more awakenings.

If the Circadian rhythms were merely reflected responses to external time cues and not endogenously produced, there would be minimal consequence to the shiftworker. As a diurnal species, humans normally sleep at night and are active during the daytime. With the availability of artificial light 24 hours a day it would seem that we should be able to easily adjust our circadian rhythms. "The existence of a biological clock in humans has been repeatedly demonstrated in temporal isolation 
studies, in which subjects are separated from all environmental and social time cues”(Wever, 1985, p. 13). A recent meta-analysis of 6-sulphatoxymelatonin rhythms in permanent night workers indicates that only a small percentage $(<3 \%)$ shows complete circadian adaptation. While studies have demonstrated that adaption can be attained, entrainment to the new sleep wake cycle must be phase shifted which is a slow process and often impeded by the need to return to day scheduling on days off from work. Two thirds of the nurses who participated in the Staff Nurse Fatigue and Patient Safety Study reported that they struggle to remain awake while on duty (Rogers, Hwang, Scott, Aiken, \& Dinges, 2004).

The single most disrupting factor to the circadian rhythm is shift work. People engaged in shiftwork suffer from 'shift-lag' syndrome, which is characterized by feelings of fatigue, sleepiness, insomnia, disorientation, digestive troubles, irritability, poorer mental agility and reduced performance efficiency (Costa, 2003).

Epidemiologoical evidence reported by Knutssen identified certain health conditions that should be considered a relative or absolute contraindication to shiftwork with strong consideration for reassignment to a day shift.These conditions are: 1 . Chronic sleep conditions, 2. Severe gastro-intestional diseases, 3: Hypertension and ischemic heart disease, 4. Insulin-dependent diabetes, 5. Thyroid and supra-renal diseases, 6. Epilepsy, 7. Chronic depression and anxiety, 8. Chronic renal disease, 9. Malingnancies, and 10. Pregnancy (Knutsson, 2003).

According to Charmane Eastman, $\mathrm{PhD}$, a physiological psychologist at Rush University in Chicago, “all of the sleep in the world won’t make up for circadian 
misalignment...The circadian clock is very stubborn and hard to push around (Price, 2011, para. 6).

\section{Physical Effects of Shiftwork}

Working the night shift and rotating shifts places not only the driver at risk for drowsy driving; the night shift and rotating shifts have been shown to potentially endanger workers' health (Dembe A.E., 2009). The health of shiftworkers has not been ignored in epidemiologic research. Numerous epidemiological studies have investigated the health consequences of working the night shift.

Together, with the cycles of light and dark, mealtimes, and social occasions are interrupted in shift workers. Circadian misalignment that is a consequence of shift work is associated with an increased risk of developing disorders of the cardiovascular, metabolic, immune, and gastrointestinal systems as well as some types of cancer, and psychiatric disorders. It was initially believed that the poor nutritional habits and lack of exercise by night shift workers were responsible for this compromised health status.

Studies conducted by Scheer (2009), charted a correlation between the work sleep cycles of night shift workers, to metabolic upheaval to disease. Scheer's research team created circadian disruption in study participants for a 28 day cycle. This brief period of disalignment resulted in multiple physical symptoms including increased blood pressure, increases in blood glucose, insulin, and cortisol levels.

\section{cardiac/cardiovascular}

In a study led by Kawachi, (Kawachi et al., 1995) an ongoing prospective cohort of 109 American female nurses aged 42 to 67 years old who had worked the 
night shift for at least three years and were free of diagnosed Coronary Heart Disease (CHD) and stroke were selected. During 4 years of follow-up, 292 cases of incident CHD (248 non-fatal myocardial infarction and 44 fatal CHD) occurred. The ageadjusted relative risk of CHD was 1.38 (95\% CI, 1.08 to 1.76) in women who reported ever doing shift work compared with those who had never done so. The excess risk persisted after adjustment for cigarette smoking and a variety of other cardiovascular risk factors. Compared with women who had never done shift work, the multivariate adjusted relative risks of CHD were 1.21 (95\% CI, 0.92 to 1.59) among women reporting less than 6 years and 1.51 (95\% CI, 1.12 to 2.03) among those reporting 6 or more years of rotating night shifts. The study concluded that there is a possibility that 6 or more years of shiftwork may increase the risk of CHD in women.

A recent study conducted by an international consortium of researchers that included Case Western Reserve University School of Medicine in Cleveland and Baylor College of Medicine explained a molecular linkage between the circadian clock and the deadly heart rhythms that can lead to sudden cardiac death (Jeyaraj et al., 2012). The researchers discovered that Kruppel-like factor 15 (Klf15), controls the level of a potassium channel-interacting protein (KChIP2), which affects how potassium flows out of heart muscle cells, known as cardiac myocytes. KChIP2 affects how potassium flows out of cardiac myocytes. Since the level of KChIP2 fluctuates during the circadian cycle, it can change the size of the protein current that controls repolarization of the cardiac myocytes. If this flow is disrupted it can lead to a change that can result in one of two cardiac problems linked to sudden cardiac death, prolonged Q-T syndrome and short QT syndrome. 
Brown et al. (2009), studied the effect of shiftwork on the incidence of ischemic stroke. The researchers used Cox proportional hazards models to assess the relation between years of rotating night shift work and ischemic stroke, adjusting for multiple vascular risk factors. Of 80,108 subjects available for analysis, $60 \%$ reported at least 1 year of rotating night shift work. There were 1,660 ischemic strokes. Rotating night shift work was associated with a $4 \%$ increased risk of ischemic stroke for every 5 years $($ hazard ratio $=1.04,95 \%$ confidence interval: 1.01, 1.07; $\mathrm{P}($ trend $)=$ 0.01). This increase in risk was similar when limited to the 1,152 confirmed ischemic strokes (hazard ratio $=1.03,95 \%$ confidence interval: $0.99,1.07 ; \mathrm{P}($ trend $)=0.10)$ and may be confined to women with a history of 15 or more years of rotating shift work. Women appear to have a modestly increased risk of stroke after extended periods of rotating night shift work.

Shift work has been associated with increased risk of cardiovascular disease. The study led by Su (2008), was designed to determine the hemodynamic effects of 12-hour shifts, and changes in blood pressure (BP) and heart rate variability (HRV) during a $36 \mathrm{~h}$ rest time following 12-hour shifts. Results showed that 12 -hour night shift work gave a persistently elevated systolic and diastolic BP (SBP and DBP) and HR compared to 12-hour day shift work with the corresponding resting time. In addition, there was delayed SBP and DBP recovery on the first 12-hour rest time in night shift workers, which was further demonstrated on the second 12-hour rest time after adjustment for possible confounders through mixed models. They concluded that 12-hour night shift work may elevate BP and HR. 


\section{cancer}

According to the International Agency for Research on Cancer (IARC), "shift work that involves circadian disruption" is considered a Group 2A carcinogen and "probably carcinogenic to humans (Straif, 2007, p. 1065).Group 2A means that this conclusion was based on "limited evidence of carcinogenicity in humans and sufficient evidence of carcinogenicity in experimental animals (Straif, 2007, p. 1065).” IARC based their conclusion on studies of long-term night workers who have shown a higher risk of breast cancer than women who do not work at night. These studies have involved mainly nurses and flight attendants (Straif, 2007). This was the conclusion of 24 scientists who were convened by the IARC to examine the correlation between shiftwork and cancer.

The impact of shiftwork on physical symptoms has been extensively studied. In a recently published nested case-control study of Norwegian nurses, an increased breast cancer risk was associated with working more than five consecutive nights for more than 5 years (Lie JA, 2011). Researchers from Harvard University found that women who worked shift work were at higher risk (50\%) of developing breast cancer, and that the longer women worked shift work, the higher their risk became (Megdala, Kroenke, Laden, Pukkala, \& Schernhammer, 2005).

Schernhammer et al. (2003) prospectively examined the relationship between working rotating night shifts and the risk of colorectal cancers among female participants in the Nurses' Health Study. They documented 602 incident cases of colorectal cancer among 78,586 women who were followed up from 1988 through 1998. When compared with women who never worked rotating night shifts, women 
who worked 1-14 years or 15 years or more on rotating night shifts had multivariate relative risks of colorectal cancer of 1.00 (95\% confidence interval $[\mathrm{CI}]=0.84$ to 1.19) and $1.35(95 \% \mathrm{CI}=1.03$ to 1.77$)$, respectively $(\mathrm{P}($ trend $)=.04)$. This study suggests that working a rotating night shift at least three nights per month for 15 or more years may increase the risk of colorectal cancer in women.

\section{orthopedic}

Feskanich et al.(2009) evaluated the association between nightshift work and fractures at the hip and wrist in postmenopausal nurses. The study population was drawn from Nurses' Health Study participants who were working full or part time in nursing in 1988. Compared with women who never worked night shifts, 20+ years of nightshift work was associated with a significantly increased risk of wrist and hip fractures over 8 years of follow-up [RR $=1.37,95 \%$ confidence interval (CI), 1.041.80]. They concluded that long durations of rotating shiftwork may contribute to risk of hip and wrist fractures.

\section{immune system}

Ackermann et al. (2012) noted that prior studies found a link between lack of sleep and the development of certain diseases and conditions, such as hypertension, obesity and diabetes and that long-term sleep loss is a major risk factor for immune system problems. The effect of shiftwork on the immune system has been studied by researchers in the Netherlands. The study compared the white blood cell counts of 15 healthy young men under normal and severely sleep-deprived conditions. Changes were seen in the granulocytes, which showed a loss of day-night levels with increased numbers, at night. White blood cell counts in a normal sleep/wake cycle were 
compared to the numbers produced during the second part of the experiment, in which blood samples were collected during 29 hours of continual wakefulness. Ackermann et al, (2012) concluded that, "The granulocytes reacted immediately to the physical stress of sleep loss and directly mirrored the body's stress response” (p. 938).

Whether working the night shift by choice or necessity, the effect of the night shift on the physical and mental state of the body must be acknowledged. People who work the night shift fight their bodies’ natural rest period while trying to remain alert and high functioning. Circadian rhythm affects hormone release, body temperature and other important bodily functions. Most nurses who work the night shift can easily attest to the fluctuation in body temperature that occurs between 3am and 6am causing them to shiver and wrap themselves in blankets.

\section{metabolic}

Pietroiusti et al. (2010) studied the effect of shiftwork and the development of Metabolic Syndrome (MS). They found that the cumulative incidence of MS was 9.0\% (36/402) among night-shift workers, and 1.8\% (6/336) among daytime workers (relative risk (RR) 5.0, 95\% CI -2.1 to 14.6). The annual rate of incidence of MS was $2.9 \%$ in night-shift workers and $0.5 \%$ in daytime workers. Kaplan-Meier survival curves of the two groups were significantly different (log-rank test; $\mathrm{p}<0.001)$. Multiple Cox regression analysis (forward selection method based on likelihood ratio) showed that among selected variables (age, gender, smoking, alcohol intake, familiar history, physical activity, and work schedule) the only predictors of occurrence of MS were a sedentary lifestyle (hazard ratio (HR) 2.92; 95\% CI 1.64 to 5.18; $\mathrm{p}=0.017$ ), and 
night-shift work (HR 5.10; 95\% CI 2.15 to 12.11; $<<0.001$ ). They concluded that the risk of developing MS is strongly associated with night-shift work in nurses.

Women doing shift work for more than six years have been shown to be at greater risk for coronary heart disease (Kawachi, et al., 1995). “The physiological impact of shift work on several markers involved in the regulation of body weight, leptin, insulin and cortisol, seems to contribute to the increased risk for the development of diabetes, cardiovascular disease and obesity,” said researcher Frank Scheer (2009, p.3) an instructor of medicine in the division of sleep medicine at Brigham and Women’s Hospital and Harvard Medical School, in Boston.

\section{psychological/cognitive effects}

The effect of shiftwork can cause major problems for nurses whose job requires a constant level of high alert and vigilance and the ability to make splitsecond, life-or-death decisions during the night. Disruption of circadian rhythms affects the psychological aspects of an employee's personality, and several trials show increased anxiety and depression symptoms (Bajraktarov S et al., 2011).

Bara and Arber (2009) analyzed longitudinal data from a British Household Panel Survey which found that undertaking night work for greater or equal to four years in men was associated with an increased risk of having a General Health Questionnaire (GHQ) score reflecting mental ill health and reporting anxiety/depression. Women were significantly more likely to report anxiety/depression and to have a GHQ score reflecting mental ill health, after working varied shift patterns for two to three years, and greater than or equal to four years, respectively. They concluded that different types of shiftwork had a differential impact 
on mental health, but this impact varied according to gender. Women's mental health was more adversely affected by varied shift patterns, while night work had a greater negative impact on men's mental health.

Owens (2007) determined that the consequences of shift work and fatigue can result in personal and family consequences. These consequences include: mood disturbances, increased stress, adverse health consequences, negative effects on personal relationships, increased potential for alcohol and substance abuse, and increased risk of motor vehicle crashes, negative effects on cognitive and neurobehavioral functioning (attention, reaction time, vigilance, memory, as well as motivation), impact on the performance of professional duties (including procedures such as intravenous insertion, cognitive tasks, and patient-related behavior such as communication skills). The reduction in quantity and quality of sleep negatively affects shiftworkers particularly in terms of social functioning and quality of life (Bajraktarov et al., 2011). Barnes-Farrell et al. (2008) collected data from four countries to determine which aspects of shiftwork influence three key indicators of off-shift well-being: work family conflict, physical and mental health. Their results suggest that various characteristics of shift schedules accounted for an additional 4.1$6.2 \%$ of the variance in well-being, beyond that already accounted for by work and family demands, and personal characteristics.

The Diagnostic and Statistical Manual of Mental Disorders (DSM), published by the American Psychiatric Association provides a common language and standard criteria for the classification of mental disorders. It is used in the United States and in varying degrees around the world, by clinicians, researchers, psychiatric drug 
regulation agencies, health insurance companies, pharmaceutical companies, and policy makers. The current version is the DSM-IV-TR (fourth edition, text revision). It is organized into a five-part 'axis' system, with the first axis incorporating 'clinical disorders' and the second covering personality disorders and intellectual disabilities. Since some individuals are seriously affected by shiftwork, there is a diagnostic category called “Shift Work Sleep Disorder” (SWSD), also referred to as shift work disorder or shift work type in DSM IV. Misalignment between internal circadian physiology and the required work schedule is thought to be a primary cause of shift work schedule induced sleepiness and sleep disruption (Akerstadt \& Wright, 2009). Working against the circadian rhythm results in extreme fatigue which decreases cognitive functions, slows reflexes, and increases feelings of irritability. This results in a diminished ability to make sound decisions as in the decision to drive while feeling drowsy or falling asleep. In addition, associated irritability, impatience and mood disorders such as anxiety and depression can negatively affect job and family relationships and have detrimental effects on social activities.

In a study conducted at Vanderbilt University, as many as 25 percent of hospital nurses go without sleep for up to 24 hours in order to adjust to working on the night shift, which is the least effective strategy for adapting their internal, circadian clocks to a night-time schedule. Changing from day to night shift often implies a period of 20-24 h without sleep. According to Dawson and Reid, the decrements in performance during the latter part of this sleep deprivation may be equivalent to an illegal level of alcohol in the blood (Dawson \& Reid, 1997). 
"Overall, night shift workers tend to get less sleep than their day shift counterparts, and their sleep is qualitatively poorer. Sleep during the day is shorter, lighter, more fragmented, and less restorative than at night, thus the night nurse arrives at work with a larger sleep deficit than does a day shift nurse (Stokowski, 2004, para. 9).”

\section{Effect of Lack of Sleep on Driving}

Although the effect of lack of sleep has been compared to the effects of alcohol, limited public reaction to drowsy driving lies in juxtaposition to public awareness of drunk driving. In a New York State survey, nearly one-half the drowsy drivers who crashed (and more than one-third of those who drove drowsy without crashing) reported having worked the night shift or overtime prior to the incident (McCartt A.T, Ribner S.A, Pack A.I., \& Hammer, 1996). Novak and Auvil-Noval (1996) found that 95\% of the intensive care nurses who participated in their examination of night shift workers $(n=45)$ reported automobile-related injuries and near accidents on the commute to and from work.

According to the World Health Organization (WHO),”...the greatest danger facing drivers is falling asleep behind the wheel. Fatigue induces poor judgment, slower reaction times and decreased alertness” (WHO, 2010, p.60). Often, shift workers are not even aware that they have fallen asleep during their commute home. By the time individuals are starting to feel fatigued and feel they may be impaired, their performance has deteriorated considerably (Jones, et al., 2006). In fact, many drivers who are involved in sleep related vehicular accidents deny having fallen asleep (Horne \& Reyner, 1998). While there may be a degree of fear of prosecution, it is 
likely that the driver does not recall falling asleep. When people fall asleep for 1-2 minutes and are awakened in Stage 1 sleep, they generally do not realize that they fell asleep.

Microsleeps are brief and unintentional episodes of loss of attention associated with events such as blank stare, head snapping, and prolonged eye closure which may occur when a person is drowsy but trying to stay awake. Microsleeps often occur during the performance of monotonous tasks like driving a car, sitting in a lecture, or staring at a computer monitor. During a microsleep, part of the brain effectively falls asleep while the rest is awake. This could account for selective loss of awareness without the person feeling he or she has been asleep (Boyle, Tippin, Paul, \& Rizzo, 2008).

In a driving simulator study, driving performance was significantly impaired in shift workers after the night shift (Akerstedt et al., 2005). Nurses who worked night or rotating shifts reported more than three times the odds of nodding-off while driving to or from work the preceding year as compared with nurses working only day or evening shifts (Gold et al., 1992). As compared to day shift workers, night shift workers are at increased risk for a sleep related motor vehicle accident due to the combined effects of driving while drowsy, driving after an extended period of wakefulness and driving at a vulnerable time in their circadian rhythm (Horne \& Reyner, 1999; Philip \& Mitler, 2000).

Professional Nursing Associations have been slow to address the issue of fatigue associated with night and shift work. The American Nurses Association (American Nurses Association, 2006) position statement on patient safety and nurse 
fatigue concludes that each registered nurse has an ethical responsibility to consider his/her level of fatigue when accepting an assignment beyond regularly scheduled work regardless of the number of hours worked.

In December 2011, The Joint Commission issued Sentinel Event Alert \#48 on Health Care Worker Fatigue and Patient Safety (The Joint Commission, 2011). The focus of the alert is to protect patients from adverse outcomes caused by fatigued health care workers. While the alert does not discuss drowsy driving per se, it does suggest actions to be taken by healthcare organizations that will help to mitigate the risks of fatigue. These actions include: an assessment of the organization for fatiguerelated risks, invitation for staff to have input into their scheduling, strategies to determine shift duration and strategic caffeine use, and education for staff regarding sleep hygiene.

The Accreditation Council for Graduate Medical Education (ACGME), responsible for the regulatory oversight of medical residency programs in the United States, has guidelines calling for residency programs to provide education to the residents and faculty in recognition of the signs of fatigue and sleep deprivation and to adopt and apply policies to prevent and counteract potential negative effects on patient care and resident learning (ACGME Guidelines, 2007). Effective July, 2011, the ACGME added the requirement for programs to include strategic napping and back-up call scheduling.

Regulations for truck drivers are governed by the United States Department of Transportation's Federal Motor Carrier Safety Administration (FMCSA). Hours-ofService (HOS) regulations allow for drivers to drive up to 11 hours in the 14 hour on 
duty window after they come off duty following 10 or more consecutive hours off duty. Drivers are prohibited from driving after being on duty 60 hours in 7 consecutive days. Drivers who operate trucks with sleeper berth are required to take at least 8 hours of consecutive time in that sleeper berth.

The Federal Aviation Agency (FAA) has aggressively addressed the issue of pilot fatigue. Taking advantage of the latest research on fatigue, the FAA created a new pilot flight, duty and rest proposal, which the agency issued on September 10, 2010. This final rule for commercial pilots includes: varying flight and duty requirements based on what time the pilot's day begins; flight time limits of eight or nine hours; 10-hour minimum rest periods; cumulative flight duty and flight time limits; fitness for duty is a combined responsibility of the pilot and the airline; and, requirements for Fatigue Risk Management training for all pilots (National Sleep Foundation, 2012).

Although working the night shift is contrary to the body's natural circadian rhythms, many nurses identify the night shift is their shift of choice. Nurses cite the following reasons for choosing to work the night shift: it allows flexibility for childcare, a strong sense of teamwork, increased hourly monetary compensation in the form of financial differentials, fewer nursing administrators on site, they are able to avoid commuting during rush hour, and, there is less activity than on the day shift resulting in a more manageable pace.

According to Dembe (2009), in healthcare, the use of overtime has increased in recent years as a response to nursing shortages in staffing. Rogers et al. (2004) noted that while most overtime is voluntary, many nurses feel compelled to work voluntary 
overtime. Night shifts are particularly difficult to fill and account for a high percentage of extra shifts that nurses voluntarily assume.

Shift work in hospital nurses is a particularly demanding example of shift-work disruption because: (i) the shifts change from on to off so frequently and (ii) most night-shift nurses strive to flip immediately back to day-activity/night-sleep on daysoff (Gamble, 2011). The ubiquitous 12 hour shift is the shift of choice by most nurses in that it allows for a three day work week. According to Rogers (2008), 75 percent of nurses work 12 hour shifts. Despite research that supports returning to 8 hour shifts, nursing administrations are reluctant to consider elimination of 12 hour shifts due to their popularity with staff nurses (Geiger-Brown \& Trinkoff, 2010) and pushback from nursing unions.

With required break time configured into the 12 hour shift, the actual time of the shift is 12.5 hours. Nurses working 12.5 hours or more had twice the odds of driving drowsy and having a motor vehicle crash and near miss when compared to those working 8.5 hours (Geiger-Brown \& Trinkoff, 2010). A significant finding of a focus group study conducted with 45 intensive care night shift nurses in a large metropolitan hospital was the discovery of an extremely high incidence (95\%) of automobile-related injuries and near-accidents that occurred while driving to and from the workplace (Novak \& Auvil-Novak, 1996).

In 2004, an AAA Foundation for Traffic Safety survey found that nine out of every 10 North American police officers had stopped a driver who they believed was drunk, but turned out to be drowsy instead. "When you are behind the wheel of a car, being sleepy is very dangerous. Sleepiness decreases awareness, slows reaction time, 
and impairs judgment, just like drugs or alcohol, contributing to the possibility of a crash,” said AAA Foundation President and CEO Peter Kissinger (2012, para. 5) According to Falleti et al.( 2003), fatigue caused greater impairment than alcohol on the speed of continuous attention and memory and learning, and on the accuracy of complex matching. For example, the deterioration in cognitive function impairment observed after 17 hours of sustained wakefulness was equivalent to that observed with Blood Alcohol Concentration (BAC) levels of 0.05\% or more (Dawson \& Reid, 1997). With 24 hours of sustained wakefulness, the magnitude of cognitive decline increased to levels equivalent to those observed with BACs of $0.10 \%$.

Nurses who work the night shift often refer to "first night on" as being the most difficult. First night is the first night shift on duty after several days off. On first night on, nurses often do not sleep prior to coming in to work, resulting in a period of 24 hours of time awake at the end of their shift. Unfortunately, rest is not tantamount in the face of competing priorities and nurses will often skip sleep before first night on.

Most studies conducted on nurse drowsiness or fatigue, focus on patient safety, examining the nurses ability to remain awake during the night shift as well as their propensity for error due to drowsiness (Surani, Subramian, Babbar, Murphy \& Aquillar, 2008; Scott, A, Hwang \& Zhang, 2006). Gold, et al. (1992), conducted a study of 687 nurses assigned to rotating shift schedules. They concluded that those nurses were twice as likely to report accidents or errors (including medication errors, work-related injuries, or accidents on the commute home), and 2.5 times more likely to report "near-miss" accidents or errors. The excessive sleepiness experienced by the 
nurses resulted in "frequent lapses of attention and increased reaction time, leading to increased error rates (p. 4).” Akerstadt (2005) found that over 50\% of shift workers reported severe decreased alertness while at work. The study authored by Folkard, Lombardi and Tucker (2005) revealed that the risk of medical errors compounds with each successive night shift worked with an error rate of 17 percent on the third successive night worked.

There is additional research on methods to counteract drowsiness during the night shift, for example, alternative scheduling methods and restorative napping. A study of restorative napping by nurses completed by Fallis, McMillan and Edwards (2011) identified personal health, safety, and patient care issues supporting the need for a restorative nap during night shift. Barriers to napping exist within the organization/work environment. These barriers can be due to lack of sufficient coverage for break times, cultural norms that disparage sleeping while at work—even while on break, and a lack of a secure and quiet space to nap.

The benefits of increased alertness after restorative napping on the night shift are varied. While some nurses have found napping improves alertness and performance (Rogers, 2005), others report the effect of “sleep inertia” after napping during the night shift. Sleep inertia is the period of decreased alertness and performance reaction that occurs when waking from sleep.

Alternative scheduling has been evaluated to increase compatibility with circadian rhythms. Rogers (2004) suggests that nursing administrators consider altering the starting times of shifts whenever possible to make schedules more compatible with circadian rhythms; to avoid scheduling employees to work more than 
two or three consecutive night shifts; and to provide adequate recovery time between shifts, especially when an employee is rotating off night shift. The National Research Report, Keeping Patients Safe: Transforming the Work Environment of Nurses (Institute of Medicine, 2003) concluded that “...the typical work environment of nurses is characterized by many serious threats to patient safety. These threats are found in all four basic components of all organizations—organizational management practices, workforce deployment practices, work design, and organizational culture (p. 3).” Nurses and nursing administrators need to be aware of the alertness decrements associated with working the night shift. Staffing patterns need should be based on the optimization of circadian rhythms.

A study conducted by Dr. Linda Scott (2007) analyzed the consequences of sleep deprivation among nurses who work the night shift. The study results demonstrated that nearly during the four week period of the study, $67 \%$ of nurses reported driving while feeling drowsy. Dr. Scott argues this study shows that nurses need to become more aware of the risks their chronic sleep deprivation and the risks of driving while drowsy. Nurses and hospital staff need to begin developing strategies to prevent drowsy nurses from driving. As Dr. Scott phrases it, "Without mitigation, fatigued nurses will continue to put the public and themselves at risk (p. 1801).”

Who is responsible when a nurse is involved in a motor vehicle accident on his/her commute home after a worked night? The common-law doctrine known as respondeat superior [Latin, Let the master answer] makes an employer liable for the actions of an employee when the actions take place within the scope of employment. The state of New Jersey currently has legislation that would bring charges of vehicular 
homicide against any driver who causes a death while knowingly driving while fatigued. According to Swinhart (2007), the profession with the most case law on driving while fatigued is the long-haul trucking industry. In most cases where a fatigued long-haul truck driver has caused an accident, the employer has been held 100 percent responsible both legally and financially. Hospitals and nurses cannot depend on the sympathy of a jury in the event of a fall-asleep accident.

The first federal bill to focus on drowsy driving was introduced in the House of Representatives in October 2002. The bill HR 5543 is called Maggie's Law: National Drowsy Driving Act of 2002. The bill was named after a young lady named Maggie McDonnell. Maggie was killed by a drowsy driver on July 20, 1997 when her car was hit head-on by a driver who crossed three traffic lanes. The driver admitted that he had not slept in 30 hours and had smoked cocaine prior to the accident. When the case went to trial, the jury was deadlocked. In a second trial, the defense argued that since there was no law against falling asleep at the wheel in New Jersey, the driver did nothing wrong. The driver received only a charge of careless driving and was fined in the amount of $\$ 200.00$.

Maggie's mother successfully lobbied the New Jersey legislature to enact a law that would punish drivers who kill or injure others as a direct result of voluntary fatigued driving. Maggie's law was passed by the New Jersey State Senate. Under that state's vehicular homicide statute, fatigued driving, defined as being without sleep for a period in excess of 24 consecutive hours, is considered recklessness. To date, no other states have been successful in enacting legislation for drowsy driving. The campaign against drowsy driving has moved into the courtroom, with law enforcement 
officials increasingly pushing to hold sleepy drivers criminally accountable when they cause fatal crashes.

According to Falleti et al. (2003), fatigue caused greater impairment than alcohol on the speed of continuous attention and memory and learning, and on the accuracy of complex matching. Alcohol was more detrimental than fatigue only on the accuracy of memory and learning. For example, the deterioration in cognitive function impairment observed after 17 hours of sustained wakefulness was equivalent to that observed with BAC levels of 0.05\% or more (Dawson and Reid, 1997, Lamond and Dawson, 1999). With 24 hours of sustained wakefulness, the magnitude of cognitive decline increased to levels equivalent to those observed with BACs of $0.10 \%$.

According to the Sentinel Event Alert issued by The Joint Commission, "Shift length and work schedules have a significant effect on healthcare providers' quality and quantity of sleep, and consequently on their job performance, as well as on the safety of their patients and their individual safety” (2011, p.1). Patients rely on care provided by nurses who may have significant impairment of their mental and physical functions due to fatigue.

\section{Potential Actions to Counteract Drowsy Driving}

Keeping Patients Safe:Transforming the Work Environment of Nurses (Page, 2004) concluded that “...the typical work environment of nurses is characterized by many serious threats to patient safety. These threats are found in all four of the basic components of all organizations-organizational management practices, workforce deployment practices, work design, and organizational culture” (Institute of Medicine, 2003). Nurses and nursing administrators need be aware of the alertness decrements 
associated with working the night shift and staffing patterns need to consider the optimization of circadian rhythms.

\section{Summary}

Our society does not believe that it is acceptable for any driver to drive in a drunken state, in fact, it is against the law. Drowsy driving, which can lead to fall asleep driving is not viewed with the same amount of societal opprobrium as driving while intoxicated. Fall asleep vehicular accidents must be prevented through greater awareness by nurses and their employers.

While the evidence suggests that the problem of drowsy driving is a strong contributor to vehicular accidents in that drowsiness portends sleep, little is known about nursing perceptions of the issue. When the literature review focused on the experiences of nurses with falling asleep on the commute home from the night shift, only a single study, (Novak \& Auvil-Novak, 1996) in part, addressed the research question of this document. Existing studies in the area of nurse fatigue focus primarily on the areas of patient safety, countermeasures to combat nursing fatigue and the physical and mental effects of fatigue and shift work on the nurse. As members of a high risk work group, nurses working the night shift merit tailored research. "Given the large number of nurses who reported struggling to stay awake when driving home from work and the frequency with which nurses reported drowsy driving, greater attention should be paid to increasing nurse awareness of the risks and to implementing strategies to prevent drowsy driving episodes to ensure public safety. "Without mitigation, fatigued nurses will continue to put the public and themselves at risk” (Scott et al., 2007, p. 1801). 
Societal changes rarely occur in response to evidence of research studies; they come from "real life" situations, experiences and stories. There is a paucity of literature focused on nurses' experience of falling asleep at the wheel after a worked night shift. This gap in the literature is significant in a time of heightened public safety awareness and increasing litigation for those held responsible in fall asleep vehicular accidents. With the lack of research related to the experiences of nurses falling asleep behind the wheel after a worked night shift, there is a need to explore this topic.

In order to continue to develop strategies to address this safety issue, it is important to explore the phenomena of drowsy driving from the nurses' perspective. This author hopes that this data will contribute to our understanding of the phenomena, which in turn, will inform the development of organizational policies.

\section{Personal Perspective/Assumptions}

In Chapters 1 and 2, this author discussed the current knowledge of the phenomenon of shiftwork and its effect on physical and psychological processes as well as its effect on driving. The existing gap in the literature, a lack of nurses' voices who have experienced this phenomenon, is justification for further study. It is also important to present what I bring to the study as a researcher so that I can put any assumptions aside and allow the situation to speak for itself.

I have been a registered nurse for 32 years. For approximately twenty of these years I have worked the night shift off and on. As discussed in Chapter 1, I was in a vehicular accident after falling asleep at the wheel. I also had numerous close calls during those periods. As a nursing administrator, I spent a great deal of time working with nurse scheduling which included allocating staff to the night shift. My experience 
as a nurse specializing in trauma, a shiftworker, a vehicular accident victim, and staffing scheduler, have led to the following assumptions:

- I believe some nurses cannot physically adapt to the night shift and in fact, are faced with significant assault to their physical and psychological wellbeing when working the night shift.

- I believe that while many nurses are frightened about the prospect of a fall asleep motor vehicle accident, they see it as part of working nights, an occupational hazard so to speak. They place other considerations, such as getting home to take over child care or the desire simply to get home to their own bed as more compelling.

- I believe that nursing administrators are largely focused on what occurs during the hours of work and on the worksite. Once the nurse in his/her car after the shift it is no longer their concern or responsibility.

- Nurse shiftworkers have few options available to them. To bear witness to their struggle allows me the opportunity to provide nursing with an insight to their struggles and explore new options.

- Practice and policy level interventions in the area of nurse shiftworkers have been largely ignored. I view this research as my personal responsibility to collect data from those nurses who are affected.

- Lastly, to be able to listen to nurses narrate their stories about their experiences with falling asleep behind the wheel as they drove home from work was not only a privileged opportunity, but an honor. My identity, my 
work experience and these assumptions have nourished my passion and commitment to this study.

It is important to state and acknowledge these assumptions. In Chapter 3, the Methods section, I will discuss how I worked with these assumptions to ensure that I was open to what the participants discussed during the interviews. 


\section{CHAPTER 3}

\section{METHODOLOGY}

The aim of this study was to obtain descriptions of nurses’ perceptions and experiences of falling asleep behind the wheel on the drive home after a worked night shift. The specific research questions were:

1. How do nurses make sense of their experience driving drowsy and (if applicable) falling asleep behind the wheel after a worked night shift?

2. What do nurses identify as factors contributing to driving home when they are at risk for falling asleep behind the wheel?

3. What suggestions do nurses have for the development of administrative policies that might address this safety issue?

\section{Research Design}

A qualitative descriptive approach was selected to address the research questions. While quantitative research can inform us on many aspects of nurses involved in falling asleep while driving on the commute home, it is limited in informing us about the experience of those nurses from their own perspective.

Qualitative research seeks to understand and explore beliefs and behaviors. The social world is seen as fundamentally different from the physical world. Human behavior is seen as being infused with meanings, intentions, motives, beliefs, values, etc., all of which must be taken into account in order to understand and explain it. The world is constructed, interpreted and experienced by people in their interactions with each other and with social systems (Maxwell, 2006). 
According to Kvale (1996), qualitative research attempts to understand the world from the subjects' point of view, to unfold the meaning of peoples' experiences, and to uncover their lived world prior to scientific explanations. Qualitative descriptive research results in descriptions of the phenomenon. It provides the researcher with the who, what, and where of events ..."without the mandate to produce anything other than a descriptive summary of an event that best contains the data collected and that will be most relevant to the audience for whom it was written” (Sandelowski, 2000, p. 339).

This method uses interpretation that is low-inference by analytically "staying closer to their data and the surface of the words and events” (Sandelowski, 2000, p. 336). Descriptions are elicited about the experience by those individuals who had the experience (Sullivan-Bolyai, Bova \& Harper, 2005). Knowledge representing the phenomenon is presented using everyday language. The picture is provided using data in the form of words rather than numbers.

The use of a qualitative descriptive approach allowed this researcher to learn more about the experience of falling asleep behind the wheel on the drive home after a worked night shift from nurses who had experienced the phenomenon themselves.

\section{The Qualitative Descriptive Method}

While other qualitative methods such as ethnography, grounded theory and phenomenology are better known, qualitative descriptive studies are also powerful. Sandelowski (2000) describes qualitative description stating, “...it is not a thick description (ethnography) theory development (grounded theory) or interpretive meaning of an experience (phenomenology) but a rich description of the experience 
depicted in easily understood language (p. 335).”

Ultimately, the findings of qualitative descriptive research can transform nursing practice by developing effective and culturally sensitive interventions and influence policy related to the issue being addressed in this study. Knowledge gained from this study can be used to illuminate potential strategies and resources while addressing the existing gap in the research.

A qualitative descriptive research design was selected for this study in order to obtain a description of the phenomena of inquiry. Two main elements consistent with qualitative descriptive studies in nursing research include: 1) learning from the participants and their descriptions; and 2) using this knowledge to influence interventions (Sullivan-Bolyai \& Harper, 2005). The major tenets of Qualitative Description are outlined in Table 3.

\section{Participants/Sample}

This study was carried out in Southern California. The sample consisted of 12 night shift nurses who had the experience of falling asleep behind the wheel during their commute home after a worked night shift. A non-probability purposive sampling technique combined with snowball sampling was used. Purposive sampling is a sampling method in which participants are selected based on purpose of the study. "Purposive sampling or judgmental sampling is based on the belief that researchers' knowledge about the population can be used to hand pick sample members” (Polit \& Tatano-Beck, 2004, p. 294).

As a non-probability sampling method, purposive sampling resulted in a group of nurses who had fallen asleep on the drive home from a worked night shift, a clearly 
defined group. Sample size selection was based on the research of Guest, et al. (2006) and his team who systematically examined data from a study involving sixty in depth interviews. They documented the degree of saturation and variability over the course of thematic analysis. Based on the data set, they determined that “...saturation occurred within the first twelve interviews, although basic elements for meta-themes were present as early as six interviews” (Guest, Bunce, \& Johnson, 2006).

After approval by the University of Rhode Island's Institutional Review Board (IRB), participants for the study were recruited by electronic mailing (email) of the 'Invitation to Participate' document (Appendix 1) to University of California Los Angeles School of Nursing Alumni. In addition, regional nursing quality consultants were provided with the Letter of Invitation to distribute to nurses in Southern California. Gaining entrée is critical in recruiting participants. Gaining entrée is defined by Polit \& Tatano-Beck (2004) as gaining access to people who can make important introductions. Two of the participants were recruited using snowball sampling. Snowball sampling is the selection of participants through referrals from earlier participants in which one person refers another (Polit \& Tatano-Beck, 2004) . Inclusion criteria for this study were:

1. Registered nurses who work exclusively on the night shift.

2. Registered nurses who believe they fell asleep while driving after a worked night shift.

Interviews were arranged with the participants via telephone or email. The participants selected a location that was conducive to the interview process in that it was quiet and afforded a measure of privacy. Each participant was provided with a 
$\$ 25.00$ gift card to Starbucks at the end of the interview as a token of appreciation for their time and willingness to participate.

Prior to the beginning of each interview, a clear description of the study was provided and informed consent obtained. At the close of each interview, permission to contact each participant was requested

\section{Data Collection Procedures}

Data was collected using a semi-structured interview guide (Appendix 4). A semi-structured open-ended interview guide was used in order to avoid limitation of responses and to encourage free expression. The guide provided a list of questions and topics that needed to be addressed during the conversation. The interviewer followed the guide, but was able to be flexible and pursue the conversation that strayed from the guide when appropriate (Polit \& Beck, 2004; Seidman, 1991). The interview questions were based on the research questions and the literature review.

In qualitative interviewing, the questions may change depending on what is learned or not learned. To allow flexibility to change questions while maintaining an overall structure, three types of questions were used: main questions, probes and follow-up questions. Prior to meeting with the participant, a list of main questions were prepared in order to begin and guide the conversation. The main questions created scaffolding for the interview, keeping the questioning on the topic, and linking what was asked in individual interviews to the overall design (Rubin \& Rubin, 1995).

When answers to the main questions lacked sufficient detail, depth, or clarity, the interviewer asked a probing question to complete or clarify the answer; to request further examples and evidence (Rubin \& Rubin 1995). The probing questions facilitate 
obtaining the level of depth the researcher wants; it can indicate that further information is needed and that the interviewer is paying attention. Follow up questions were asked in order to attain the depth of information requested by the researcher. All questions should be worded such that the participant understands the question focus.

The use of a responsive interviewing technique was guided by Rubin \& Rubin (2005). Responsive interviewing aligns with the philosophical beliefs of the researcher in that it relies heavily on the interpretivist constructionist philosophy. According to Rubin \& Rubin (2005) “The responsive interviewing model emphasizes that the interviewer and the interviewee are both human beings and not recording machines, and that they form a relationship during the interview that generates ethical obligations for the interviewer (p.30).” The goal of responsive interviewing is to generate a depth of understanding. A solid and deep understanding is preferable to a large breadth. Additionally, in responsive interviewing, the design of the research remains flexible throughout the project” (Rubin \& Rubin, 2005, p. 30). This flexibility is essential in attainment of a depth of understanding. The main characteristics of Rubin \& Rubin's Responsive Interviewing Model is detailed in Table 4.

The decision to interview implies a value on personal language as data (Newton, 2010). Face-to-face interviewing was selected in order to obtain depth of meaning and context. The interviews varied in length from 40 minutes to one hour. The interviews were carried out in a conversational style based on Rubin \& Rubin's conversational partners approach. Settings varied from coffee shops to conference rooms. These settings were mutually negotiated by the researcher and participant. The 
times and dates of the interviews were also negotiated between the researcher and participant.

Each of the interviews was tape recorded. "Electronic recording can distract both the interviewer and interviewee and influence what people say so you want to make the recording as smooth and unobtrusive as possible” (Rubin \& Rubin, 2005, p. 111). During each interview, the interviewee was informed when taping began and ended. The small digital tape recorder was placed in a location that was not conspicuous.

Digital tape recordings of each interview were transcribed into a typed document by a professional transcriber. Names of the participants were removed and replaced with participant numbers. Each individual recording was assigned a code number by the investigator. Only that number appears on the typed transcripts. Names and contact information was kept on a secured and encrypted flash drive that could only be accessed by the investigator. No other individual has/had access to the names with the associated participant numbers.

Once the interviews were transcribed, a copy of each participant's transcript was sent in order for them to verify accuracy. All participants reviewed their transcripts and provided feedback via email as to whether or not the transcript had accurately captured the content of the interview. This process was conducted to address trustworthiness. Of the twelve participants, 11 responded either with complete agreement or minor clarifications. One respondent had discussed an identifying characteristic of her place of employment and asked that this be removed. 
The orientation of the researcher to the subject is critical to the success of the study. According to Rubin \& Rubin (2005), "Rather than pretend that interviewers come into the situation with no biases and can listen to answers without sifting them through their own experiences and cultural lenses, the responsive interviewing model argues that researchers need to continually examine their own experiences and cultural lenses; the responsive interviewing model argues that researchers need to continually examine their own understandings and reactions” (p. 31). This researcher used a detailed reflexive journal throughout the study. The journal entries were completed immediately after each interview. The journal was used to record personal experiences and observations regarding the data and interviews. The journal helped to sort out ideas that evolved from participant to participant and assisted this researcher in identifying emerging themes and when data reached saturation. The journaling process also provided a way for the researcher to de-brief after each interview.

\section{Data Analysis}

"Data analysis is the process of moving from raw interviews to evidence-based interpretations that are the foundation for published reports” (Rubin \& Rubin, 2005, p. 201). The process of analysis included classifying, comparing, and weighing of meanings to reveal patterns and descriptions. While the analysis was based on the descriptions presented by the interviewees, the interpretations were those of the researcher (Rubin \& Rubin, 2005).

The theoretical framework of social constructivism guided the analysis of data. In alignment with the qualitative descriptive method, the aim of the analytical process and presentation of the data was to remain close to the data (Sandelowski, 2000). 
Whereas other qualitative approaches often aim to develop concepts and analyze data using reflective or interpretive interplay with existing theories, the final product of qualitative description is a description of informants' experiences in a language similar to the informants' own language (Neergaard, Olesen, Andersen, \& Sondergaard, 2009).

Inductive manifest and latent content analysis was used to analyze the data. Content analysis is a method of gathering and analyzing the content of written, verbal or visual communication. This method can be used with either qualitative or quantitative data and in an inductive or deductive way (Elo \& Kyngas, 2008). In inductive content analysis concepts are derived from the data. In deductive content analysis the structure of analysis is operationalized on the basis of previous knowledge (See Figure 1). Inductive content analysis is used in cases where there are no previous studies dealing with the phenomenon or when it is fragmented. A deductive approach is useful if the general aim is to test a previous theory in a different situation or to compare categories at different time periods (Elo \& Kyngas, 2008).

According to Graneheim \& Lundman (2004), a characteristic of qualitative content analysis is the method focuses on the subject and context and emphasizes differences between and similarities within codes and categories. The content analysis approach adheres with the naturalistic paradigm in that meaning is derived from the context of the data. "A basic issue when performing qualitative content analysis is to decide whether the analysis should focus on manifest or latent content.” Manifest content analysis deals with content and describes the visible and obvious components. Latent content analysis deals with a relationship aspect and involves interpretation of 
underlying meaning of the text. "Manifest and latent content both facilitate interpretation but vary in depth and level of abstraction” (Graneheim \& Lundman, 2004, p.106).

Given that inductive content analysis was the selected method, the next step was to organize the data. Each transcript was read and re-read multiple times to obtain a sense of the content and the meaning. The goal in reading and re-reading the data was to obtain a sense of the whole (Graneheim \& Lundman, 2004). The process involved open coding, creation of categories, and abstraction. Open coding was accomplished by reading through the transcript and writing notes and headings directly onto the transcript. Multiple headings and notes were written in order to identify categories and themes.

After open coding was completed and intercoder reliability established, the lists of categories was grouped under higher order headings. The primary aim of grouping data is to reduce the number of categories by collapsing those that are similar into higher categories. For this study, initially all of the codes were taken from the twelve transcripts, written onto post-it notes and grouped them into tentative categories. They were left for a two week period in order for this researcher to immerse or "dwell” in the data. During the two weeks, the post-its were arranged and re-arranged into categories. According to Polit \& Beck (2004), researchers whose aims are primarily descriptive tend to use categories that are fairly concrete, e.g., the category scheme may focus on differentiating various types of actions or events, or different phases in the unfolding of an experience. In order to develop the category scheme, related concepts were grouped together to facilitate the coding process. When 
categories are formulated through inductive content analysis, the researcher decides, through interpretation as to which things belong in the same category (Dey, 1993). It is important to note, that creating categories is not simply bringing together observations that are similar or related. The data is classified as 'belonging' to a group (Dey, 1993). The purpose of creating categories was to provide a means to describe the phenomenon.

The process of abstraction entails the formulation of a general description of the research topic through the generation of categories (Elo \& Kyngas, 2008). "Each category is named using content-characteristic words (Elo \& Kyngas, 2008, p. 111).” Through the extraction of common themes from the data, some differences stood out. While many of the participants felt frightened when awakening to the honking of horns by other motorists, one participant felt extreme anger. These differing viewpoints about an emerging theme regarding being awakened led me to investigate other differences that I may have overlooked in the data.

In sorting the content into themes a coding scheme was developed. This coding scheme was used to reorganize the themed content into manifest content. The next step was to engage in latent coding. Of note, the researcher cannot make inferences regarding intent or motivation on the part of the participant. Content analysis is only that which is in the transcripts. One cannot infer intentional bias or intended effect from the data.

After sorting through multiple codes and categories among the data, 3 to 5 quotes or meaning units, for each category and theme were selected. At this point, these meaning units evolved into condensed meaning units and eventually into codes 
(See Tables 3, 5-11). For example, participants recounted their experiences with having no recollection as to how they arrived at their home. They recounted a feeling of lost time. The analysis indicated that these could be explained with one code. In essence, the meaningful units were condensed into meaning units and then into a code. Table 1. Examples of meaning units, condensed meaning units, and codes

\begin{tabular}{|c|c|c|}
\hline Meaningful Units & Condensed Meaning Units & Code \\
\hline $\begin{array}{l}\text { I would just be rolling up to the } \\
\text { stop sign right before my house, } \\
\text { and sort of awaken if you will, } \\
\text { and be like, "How did I get } \\
\text { here?" }\end{array}$ & How did I get here? & \multirow{5}{*}{ Auto Pilot } \\
\hline $\begin{array}{l}\text { “...that day I just remember } \\
\text { driving and I don’t even } \\
\text { remember how I got home.” }\end{array}$ & $\begin{array}{l}\text { Don’t even remember how I } \\
\text { got home }\end{array}$ & \\
\hline $\begin{array}{l}\text { “...there were days that I was on } \\
\text { auto pilot, so it was almost like I } \\
\text { went through my daily routine as } \\
\text { that, as a routine without really } \\
\text { um, recalling. Like, this has been } \\
\text { done, but I don't remember } \\
\text { doing it.” }\end{array}$ & $\begin{array}{l}\text { On auto pilot without recall } \\
\text { of daily routine }\end{array}$ & \\
\hline $\begin{array}{l}\text { “...it was maybe I don’t know all } \\
\text { of ninety seconds to two minutes } \\
\text { or something that I can’t account } \\
\text { for.” }\end{array}$ & $\begin{array}{l}\text { Ninety seconds to two } \\
\text { minutes or something I can } \\
\text { account for }\end{array}$ & \\
\hline $\begin{array}{l}\text { “I’m not like aware of my - my } \\
\text { surroundings. Sometimes I don’t } \\
\text { know if it’s like already, um, a } \\
\text { routine, that my body just takes }\end{array}$ & $\begin{array}{l}\text { My body just takes me } \\
\text { home }\end{array}$ & \\
\hline
\end{tabular}




\begin{tabular}{|l|l|l|}
\hline me home. “ & \\
\hline $\begin{array}{l}\text { "But when you go there it's } \\
\text { you're just there. Not really } \\
\text { being there” }\end{array}$ & Not really being there. & \\
\hline
\end{tabular}

A total of eight codes emerged from the iterative process of coding the data. The qualitative content analysis process offered this researcher several benefits. It provided the researcher with an in-depth description of the phenomenon of falling asleep behind the wheel on the drive home after a worked night shift.

Qualitative content analysis is not a linear process. T “Qualitative analysis is more complex and arduous than quantitative analysis, in part because it is less formulaic (Polit \& Tatano-Beck, 2004, p. 570).” The researcher initially utilized the Vivo software program to organize the data, however, manual indexing was selected to organize and code the data in that it physically brought this researcher closer to the data. As mentioned earlier, the use of post-it notes physically posted on this researcher's walls allowed for easy grouping and regrouping allowing engagement in an iterative process that was visual and easily manipulated into different categories. Dwelling in the physically represented data, prevented the risk of premature closure of analysis.

\section{Achieving Trustworthiness}

The findings of qualitative research studies must be as trustworthy as possible. Lincoln and Guba (1985) note that credibility is the 'overriding goal' of qualitative research. Credibility refers to confidence in truth of the data (Polit \& Tatano-Beck, 2004). It addresses how well data and the process of analysis address the intended 
focus. According to Lincoln and Guba (1985), credibility involves two aspects, performing the study in a manner that enhances the believability of the findings and secondly, proceeding in a way that demonstrates credibility to consumers.

In order to produce credible data and subsequent interpretations, prolonged engagement in the collection of data was afforded this study. The twelve interviews were collected over a period of six months. Sufficient time was allotted for collection of the interviews, as well as the actual interviews themselves. It was important for this author to take the time to build a rapport with each participant prior to the beginning of the interview.

The aim of trustworthiness in a qualitative inquiry is to support the argument that the inquiry’s findings are "worth paying attention to" (Lincoln \& Guba, 1985). This author and a member of her dissertation committee independently coded the data. Discussion of the codes with a re-examination of the data occurred until there was 98\% agreement. Neuendorf (2002) states that when human coders are used in content analysis, the reliability translates to 'intercoder reliability' as a critical component of content analysis. Intercoder reliability is defined as "the extent to which independent coders evaluate a characteristic of a message or artifact and reach the same conclusion” (Lombard, Snyder-Duch, \& Bracken, 2005, para. 2). While intercoder reliability does not assure absolute validity, if it is not properly established, the interpretations cannot be considered valid (Nuenendorf, 2002).

An audit trail was conducted by a member of the dissertation committee. "An audit trail involves scrutiny of the data and relevant supporting documents” (Polit \& Beck, 2008, p. 545). Although this is a tedious and complex process, it is an 
important tool in addressing confidence in study findings (Lincoln \& Guba, 1984;

Polit \& Beck, 2008).

Nature and Limitations

All methods of research have their limitations. In this study, the sample consisted of 12 nurses who lived in Southern California. Although this sample is limited, the quality and depth of the comments did answer the research questions. The low inference approach of qualitative description does limit the ability to generalize.

All of the participants work in the state of California. California is the only state in the United States that has enacted legislation calling for the same unit specific nurse to patient ratios to be utilized in all nursing units. It could be construed that with favorable staffing ratios, the nurses experience of drowsy and fall asleep driving does not reflect that of those nurses working in conditions with higher nurse to patient ratios. The exclusion of participants from other states could be considered a weakness of the study.

An additional limitation of the qualitative approach is that the findings cannot be generalized to wider populations with a high degree of certainty. The findings of qualitative research are not evaluated for statistical significance.

In the analysis of qualitative data, no theoretical attachments are made. This allows the analysis to stay close to the data (Sandelowski, 2000). A limitation is that the analytical process seems subjective in that it depends on the researcher's perceptions. However, it is the best way to gain insight into the participants' views of the phenomenon. 


\section{Ethical Considerations}

Participant confidentiality was a priority in this study. Interviews took place in a location that provided privacy and was agreeable to each participant. Audio tapes were kept in a locked file until transcribed. Audio-taped interviews were destroyed after they had been transcribed and the transcriptions were entered into a password protected computer. Interviews were coded for identification. These codes and demographic data were currently kept in a locked file, separate from transcriptions. All transcriptions, consents, demographic data, and key codes will be destroyed after three years. This information, regarding data management, was presented to all interview participants prior to the interview.

\section{Human Subjects}

Approval from the University of Rhode Island Institutional Review Board was obtained on May 18, 2012.

\section{Summary}

In summary, the qualitative descriptive approach provided strong conceptual descriptions and an understanding of falling asleep behind the wheel on the drive home from a worked night shift. 


\section{CHAPTER 4}

\section{FINDINGS}

The results of this study are based on twelve interviews with nurses who had experienced falling asleep behind the wheel on the drive home from work after a worked night shift. Data collection involved face-to-face interviews in which the participants were asked to reflect on a time when they fell asleep behind the wheel driving home from work. Cognitive probes were utilized throughout the interviews to elicit details regarding each participant's experience. Qualitative content analysis was used to analyze the data and eight themes emerged.

In the following sections, a synthesis of the qualitative content analysis of the data will be presented. This was achieved in collaboration and with Drs. Marlene Dufault and Ginette Ferszt. Discussion of the data is presented from the perspective of the themes emerging within the research questions posed in Chapter 1.

\section{Demographic Data}

Demographic data from a purposive sample of 12 Registered Nurses working the night shift in the Southern California area of the United States is described below. One participant did not submit her data which had been requested electronically.

\section{Frequency and Percentage Distribution of Registered Nurses}

Table 2. Demographics

\begin{tabular}{|c|c|c|}
\hline \multicolumn{2}{|c|}{ Total Sample $\mathrm{n}=11$} & $\mathrm{n}$ \\
\hline$\underline{\text { Age (years) }}$ & & \\
$21-25$ & 2 & 18.2 \\
$26-30$ & 5 & 45.4 \\
$31-35$ & 2 & 18.2 \\
$36-40$ & 1 & 9.1 \\
\hline
\end{tabular}




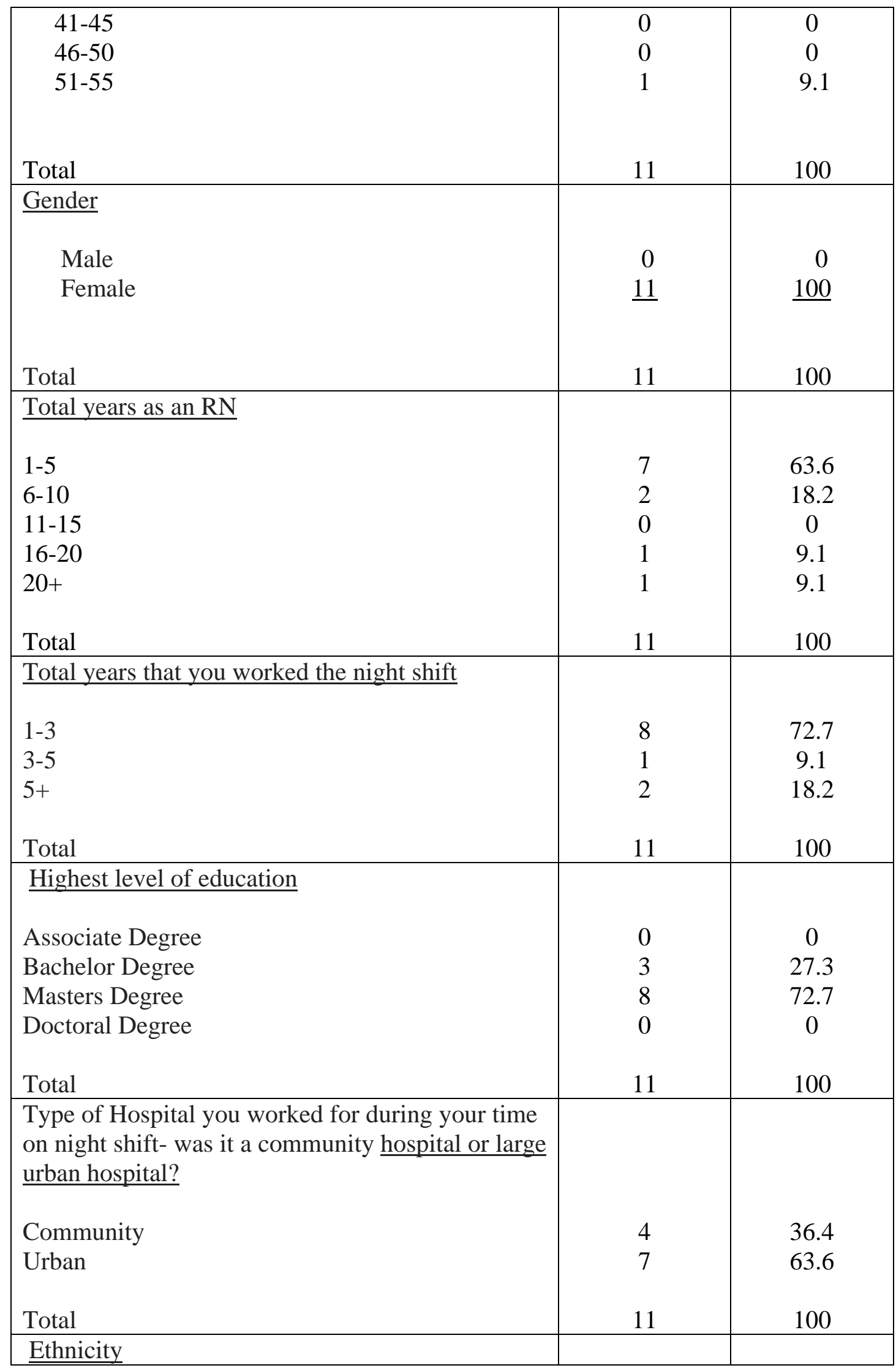




\begin{tabular}{|l|c|c|}
\hline Caucasian & 3 & 27.3 \\
African-American & 1 & 9.1 \\
Asian & 3 & 27.3 \\
Hispanic & 3 & 27.3 \\
Other & 1 & 9 \\
Total & 11 & 100 \\
\hline Married or single & & \\
Married & 3 & 27.3 \\
Single & 8 & 72.7 \\
Total & 11 & 100 \\
\hline
\end{tabular}

The experience of falling asleep behind the wheel was described by each of the participants in their own voices. The nurses demonstrated an openness and eagerness to share their stories. The following eight themes emerged: (1.) night shifts better for new grads, (2.) auto-pilot, (3.) struggling to stay awake, (4.) it's scary, (5.) just need to get home, (6.) not a night person, (7.) feeling awful, and (8.) don’t know how to fix it. The development of the themes as described in the voices of the participants provided rich descriptions of their experiences with regard to the research questions. Direct quotes from the participants are provided to allow the reader to reflect on the participants responses to the interview questions. Each of the eight primary themes is discussed in the next paragraphs.

\section{night shifts better for new grads}

This theme was generated by responses to the research question “Are there any specific reasons that you are working the night shift?” Three patterns of the data were categorized from this question which illustrate the participants' experiences; having only night shift positions available to them as a new graduate; feeling that the pace of the night shift was more conducive to their learning and acclimation to practice; and 
feeling that there is more support and teamwork on the night shift as opposed to the day shift. Most of the nurses identified the reason they worked or had worked the night shift as a lack of shift choice available to them as a new graduate nurse. Despite this, it was clear that the tempo and atmosphere of the night shift was better for a new graduate. One participant described an experience that she had while orienting on the day shift. She felt that the pace on the night shift was conducive to providing the type of patient care that she felt was needed.

“...but as a new graduate, the workload is crazy on days, so I thought ... I felt that I could do a better job working nightshift. I could actually have time to read the HPs, learn about my patients, look up patient histories, look up diseases that I didn’t know. During the day, like I had a Code once, and I was like, I feel like I just got report and something happened, and don’t know, I feel like I don’t know anything about it. It's like, “What's the history? What happened?” I'm not sure all of that. It's like, the report's a big blur, and patient's not responsive. That's all I know. So, I'm much more efficient now. I think I'd probably do just fine on days, but I just feel that I provide better care at night. I have the time to sit down and talk to my patients about what's going on, about their procedures, explain about their meds, things that I didn’t get a chance to do on dayshift.”

Another participant discussed the requirement for all new graduates to do the night shift in order for them to become familiar with policies and complete required competencies. 
"Yes, it's not by choice I can tell you that. Um, all new hires on my unit NICU have to go to nights. Usually because the pace on average tends to be slower because there's not as many surgeries coming out as there are during the day. Um, there's more time to go to the competency pathways and the policies and procedures. So they start us all off on nights in precept. And then we have to do at least a year on nights before we can transition to days. So my year is coming up this fall. So I'll have a meeting with my manager to see if I can move to days."

Relationships with colleagues on the night shift were an important factor in the support of new graduates on the night shift. Confidence that their colleagues would be supportive and mentor them was a positive factor despite the many stated negative effects of the night shift. There was praise for the support that new graduates received on the night shift as well as less stress with the pace of the night shift. There is a relationship that is both interpersonal and professional.

“I've had the option to move to days, but the nightshift, the people that I work with is one of the major reasons, to (stay on nights). Because we work as a team at night. It's a little different during the day. I just ... I think also being like a newer nurse I will ... I have all this work, and my nurses, I could go to and they would help me. So, that's a major reason.”

One participant discussed her hesitation to go to days although she had completed her requisite time on the night shift. The relationship with her night 
colleagues resulted in a commitment to the night shift despite the physical stressors she experienced working the night shift.

"I worked about four and a half years of nights. Maybe after the third and a half year or so... I actually wanted to go to days longer than I had been looking for a day job. But the day shift nurses were so different and I didn't like being around when administration was there. It's just different working days. So I liked the vibe on nights."

The statements made by the participants with regard to the teamwork and support received on the night shift revealed consistency with literature findings validated by the Joint Commission statement on the importance of teamwork for safe patient care. "Teams whose members have experience working together know each other's strengths and weaknesses, and can better support each other and compensate for each other-even under extreme stress and fatigue conditions. They know how to balance each other out and they know that others are available to complement their strengths and weaknesses, which may also lead to lower stress levels for all participants” (The Joint Commission, 2003, p. 12). According to a night nurse quoted in an article by Domrose (2006, para. 4), "Because there are fewer people on the night shift, the nurses tend to rely on each other more...people will jump in and help without being asked.”

The participants feared they would not receive that if they were changed to a different shift. All but three of the participants stated that they had been required to start on the night shift when they were new graduates. The most consistent thread throughout the data was that the pace and collegial support present on the night shift 
helped the new graduate make the transition from graduate novice nurse to experienced and proficient nurse smoother.

\section{auto-pilot}

This theme was both puzzling and frightening to many of the participants.

They shared their experiences of having no recollection of passing exits or of parts of the drive home. They weren’t sure what had transpired. Had they fallen asleep or just become unaware of their surroundings? One explanation for this may be the occurrence of microsleeps. As discussed in Chapter 2, microsleeps are episodes that occur when a person is fatigued and trying to stay wake. During these episodes which may last only seconds, the individual is not aware of external information and may have no recollection. In essence, there is a feeling of missed time and the individual may come to realize they have "missed” a part of their drive. These episodes are frightening when you realize that at 70 miles an hour a car travels 102.5 feet per second. If the driver falls asleep or experience a microsleep that lasts 3 seconds, they have traveled a little more than the length of a football field.

“There were times where, obviously I don't recall at what point that happened, but then I would just be rolling up to the stop sign right before my house, and sort of awaken if you will, and be like, "How did I get here? And that was ... that was very scary.”

Most participants shared some stories of their inability to remember how they got home or being on "auto-pilot.” 
“...there were days that I was on auto pilot, so it was almost like I went through my daily routine...without recalling. Like, this has been done, but I don’t remember doing it.”

“Oh my God, I'm in my garage and my engine is on, and I'm asleep.” “I-I don’t remember pulling in here.”

“I don’t remember. You know what; I really don’t. It was like a black out. I really don’t remember.”

“...it was maybe, I don’t know all of ninety seconds to two minutes or something that I can’t account for.”

“I don’t want to say I opened my eyes because I don’t even know that I closed my eyes. But when I realized what was going on around me I was two exits past my exit and I didn't know how I got there. And like my heart skipped a beat and I was really scared because I honestly did not remember driving.”

“Um, but there was several times where I dozed off and I don’t remember how I got to where I was going. You're on autopilot or something. I'm very fortunate that I didn't get in an accident. And yeah, it's-it's shocking that you can drive your way home while you're 
asleep, or in this half ... in this half-awake, half-asleep state, I'm not quite sure what it is.”

When describing the experience of not remembering, or feeling like they were on auto-pilot, the participants relayed to the researcher their feelings of being frightened when they realized they had lost time, missed exits, or lost awareness of the atmosphere around them. Immediately after this realization, some participants described feeling their hearts pounding and becoming shaky as with a sudden adrenaline rush. Yet, they noted that they were soon, once again feeling the effect of overwhelming sleepiness shortly after the episode.

The oddness of the experience is largely due to the knowledge that there is a missing piece of time in their temporal awareness. Other terms used to describe this phenomenon are: driving without awareness, highway hypnosis, white line fever, and time gap experience. When describing this phenomenon some of the participants described their distress and became visibly distressed. "After a long drive the motorist will commonly report that at some point in the journey he "woke up" to realize that he had no awareness of some preceding period of time” (Goleman, 1979). This experience was echoed by the participants. These periods of no recollection pose a serious threat to driver safety and left the participants feeling unsettled and anxious. struggling to stay awake

All participants were at risk for fall-asleep accidents because they suffered from sleep deprivation. The participants universally discussed feeling tired while driving home. They relayed difficulties sleeping during the day, at times getting as 
little as three to four hours per day or conversely sleeping all day and not feeling rested.

"You know, so I think after that shift when I was coming back I think I must have slept at least ten times during my entire journey back home. I think; at least if not more. I can’t count for sure.”

The feelings of overwhelming fatigue were undeniable. The participants discussed their struggle to stay awake during the drive home. Staying awake and alert on the drive home was physically impossible.

“I couldn't open my eyes driving, I couldn't, I could barely, they like feel so heavy. You couldn't, you couldn't like, I was holding my steering wheel with two hands like this and I couldn't open my eyes sometimes.”

"I went from first lane to the fourth lane and hit the sidewalk and hit a bicyclist. Woke up to a noise. I told him "I think I fell asleep” (the participant had struck a bicyclist).

The nurses described ways that they tried to fend off the strong urge to sleep. They described various methods such as: "so you turn on the radio really loud, you roll down the windows, you'd be singing, you'd be dancing, you'd just, I mean, I-I did slap myself, my face, uh, my legs. Just constant movement”; drinking coffee before the drive home; "I had a strong shot of coffee with me. Um, I had music loud initially but then it's not working; I thought maybe I can start singing to myself or talking to 
myself or something. You know and so I was trying-but I fell asleep behind the wheel in between two trucks.”

"Yeah, the fatigue that you experience is-is just like no other."

Two of the participants routinely had family members bring them to work and pick them up after work. While the researcher was interviewing one of the participants on the morning after a worked night shift, the participant paused the interview twice to answer a call from her mother who was calling to check on when she needed to come to pick her up. Her mother was concerned that perhaps she might catch a ride with another fatigued colleague.

According to Stanford Sleep Expert Dr. William Dement (1997), “The powerful brain mechanism that regulates the daily amount of sleep is called the sleep homeostat. By increasing the tendency to fall asleep progressively in direct proportion to the increasing size of sleep debt, this homeostatic process ensures that most people will get the amount of sleep they need, or close to it. The elevated sleep tendency together with associated drowsiness and an intense desire to sleep would ordinarily prevent most people from becoming dangerously sleep deprived because they would go to bed early or sleep late, when such excessive daytime sleepiness occurred” (Dement, 1997, para. 7).

When the nurse has not had a sufficient amount of sleep and resists the signals from the sleep homeostat, the urge to fall asleep becomes insurmountable. The signals from the sleep homeostat coupled with driving can result in tragedy. 


\section{it's scary}

During their drive home after work, the participants were exposed to fall asleep driving and realized that they were at risk for involvement in a fall-asleep crash. Many of the participants believed that they were fortunate to be alive.

“And there are a lot of times that like, thank God nothing happened to me. I haven't gotten in an accident, but I don’t want it to happen.” 'I still dozed off or got home and fell asleep in my garage... which is even I think a little more scarier than falling asleep on the road.’

Participants discussed the feelings after a near miss. In a study conducted by sleep expert Dr. Charles Czeisler, hospital interns who had been scheduled to work for at least 24 consecutive hours increased their risk of a near miss $460 \%$.

"It was so horrible. It was such a nauseating experience. It was so frightening.”

"I tend to be a really spiritual person so I was like praising God for sparing my life because I could've killed myself and a bunch of other people too um, and... I mean I still think about it to this day.”

“...all day on Sunday I was like shaking, very shaky and overwhelmed and I kept thinking like wow, what happened, did it really happen? (she crossed several lanes and struck a bicyclist-without recollection).

The near-miss is not without consequence to the driver. The sense that a person is in imminent danger triggers the dramatic emotional/physical response of the sympathetic nervous system response called "fight or flight.” This is followed 
immediately by the release of adrenaline and cortisol. Blood pressure rises and the heart rate accelerates. This response to imminent danger can leave lingering effects of shakiness, digestive upset and unclear thinking.

\section{just need to get home}

Many of the participants cited the need to "just get home after work.” They were not motivated to pull off the road and take a nap or stop for a cup of coffee. Instead, they tried playing the radio loudly, moving about in their seats, slapping their cheeks in order to stay awake long enough to get home. "Research has shown that most such activities (opening the window, increasing the volume of the radio, etc.) at best, can postpone sleep for only a few minutes. The only effective countermeasure against sleepiness is sleep, preferably combined with a caffeine drink” (Sagberg, Jackson, Kruger, \& Williams, 2004).

"And but the reason why I would wake up is because the carpool lane bumps. So when I'm - I'm swerving or whatever I'm doing between those three or four seconds of what I would call a sleep I'd wake up and I - my heart was just adrenaline rush. I'm like -- don't do that, but I couldn't help it because I'm so tired and it - I'm almost home and my focus is just get home so I can knock out.”

"I could really get in trouble if I let myself do this. I need to somehow stay awake and just make it the extra couple minutes back.”

The following participant revealed that her need to get home super-ceded the laws to stop at stop signs and red lights. She ran through several lights and stop signs 
despite other motorists honking their horns at her. She recounted that on one level she was aware of what she was doing but she didn't care. When she thought about it later it frightened her.

“I don’t even remember how I got home but I know that I passed some red lights. I heard cars honking at me, but I was so sleepy that I didn't even react to it. It didn't even like scare me. It was just, "I need to get home” I was so sleepy that I didn't even react to it - it was just, I need to get home.”

"I’d drive fast going home and I mean I hate to say it, I mean good thing no cops have ever really pulled me over, just to get home and I just wanted to be home. I think that was my-my-my focus was just get home and so I can sleep.”

According to a recent report on drowsy driving by the (Centers for Disease Control and Prevention, 2013), drowsiness impairs decision making skills. Driving excessively fast or running stop signs and lights in order to get home were not routine behaviors for the participants when they were not driving drowsy. The associated sleep debt along with an overwhelmingly strong urge to sleep served to impair judgment with regard to personal and public safety.

\section{not a night person}

While there are nurses who seem to thrive on the night shift and would not consider changing to the day shift, for most people, staying awake through the night is struggling to fool the bodies' natural circadian rhythm. Deviations from the norm of nocturnal sleep leads to problems in the quality and quantity of sleep. During the 
daytime, sleep is of poorer quality and quantity than when taken at night (Arendt, 2010) . "Most permanent or long-term night shift workers do not adapt their circadian system to the imposed work schedule. A recent meta-analysis of 6-ulphatoxymelatonin rhythms in permanent night workers indicates that only a small percentage $(<3 \%)$ shows complete circadian adaptation” (Arendt, 2010, pp. 13-14).

Throughout the interviews, many of the participants noted that other nurses seemed to adapt well to shiftwork and did not complain of falling asleep on their drive home.

“I'm not a night person. I realized after working night shift I'm not a night person at all.”

"I feel like I am one of the people who is more tired in the morning. I feel like everyone else when they leave work it doesn’t look like...you know some people even go out to breakfast after work with each other. I can't do that. They go out and they have like Mimosas and they have breakfast on the waterfront. And they, I always get invited and I've never gone in the year I've been there because I just I wouldn't be able to drive home afterwards.”

"You know that, I mean some, some of my friends were completely okay with it, they didn't have any problems. I think I was probably, me and another girl were the ones that was struggling the most. You know they would, they would say oh you know I go home, take my family, 
spend time with my mom and then wake up, sleep for two or three hours before the night, the next day and I'm like God, how do you do that? How do you do that? “

\section{feeling awful}

The theme of "feeling awful" encompasses feelings of social isolation and a lack of physiological and psychological wellness. Shift workers do not have time for social activities. "Work is the central factor in creating sleep deprivation for shift workers. Their schedule revolves around work, which is frequently taking place at a time when their family and friends are asleep. To interact with these people, shift workers have to sacrifice something, usually sleep” (Nelson, Isaac, \& Graham, 1998, Key Findings).

"And the other hard thing was um, still trying to socialize with people who have a regular day job. So you get off work on a Saturday morning and you want to go to bed because you're extremely tired but there's a birthday party going on. Or there is, you know whatever... so there's a lot of sleep deprivation if you want your social life to continue”.

Participants discussed feeling socially isolated from friends and family.

"Half the time you don't listen to what the other person is saying. And I think most of the consequences; well the brunt of my night shifts was borne by my family. I think because in the hospital, you know, when you're working you've got to put on a professional self so you-you are trying to be the best you can to project what you are at work. And then 
when you go-go home you vent everything out. It's the kids; you don’t want to talk to them. It's your husband; you don't want to talk to, you don’t want to see him. “

Several of the participants working nights initially believed that the night shift would allow them to spend more time with their families. Instead, they found that their level of patience and desire to be social was low due to fatigue.

Healthy patterns of nutrition and exercise were compromised as well. Participants spoke of either gaining weight from eating nutritionally deplete vending machine food or eating less overall and losing weight. Those who had exercised on a routine basis found it difficult to fit into their schedules.

"From personal experience I think your nutrition suffers. I see a lot of really poor eating habits on my night shift. You tend to want to eat sweet and savory foods at three in the morning. It's harder to eat something like a salad or a sandwich. Um, and you come home in the morning and you don't really have an appetite because your circadian rhythms are off. And so when that doesn't match up you don't have the same hunger schedule almost. So I actually found when I started nights I-I lost probably about ten pounds. Yeah, I wasn't eating healthy and I would go home and I was so tired I couldn’t even make breakfast when I got home. Um, so on that level; on a fitness level you don't want to work out when you come home. You don’t want to work out before you go to work because you're trying to maximize your sleep. So it really leaves you know three, three and a half days a week to exercise 
which you know we know as nurses is not enough for that thirty hours a week you're supposed to get.”

The participants discussed responsibilities related to work and family, their schedules are very tight, with little room to do much else.

“Um, and so I was tired, just completely exhausted. I had circles under my eyes, my ... I was just overall unhealthier, dry skin, you find yourself crabby.”

I couldn't take care of myself, I couldn't, I could barely eat. I could, I was just very irritated most of the time you know? You just feel like you're not, you're not your best you know you're not, you're not doing the best you can because you're just very tired and you know your physical needs are not met so your mental needs are not met either, you know”.

Several of the participants who were not married and did not have children were surprised at those nurses with families. They felt that they could barely care for themselves. Several of the participants lived at home with a parent who in essence took care of them by providing meals, transportation and the time to sleep uninterrupted during the day.

All twelve participants had either come off of the night shift or were planning to come off shortly. Two of the participants had left their night positions and relocated out of state in order to secure a day position. While all of the participants felt more comfortable on the night shift, they all either left or planned to leave as soon as they 
could in order to secure a day position. The compromise in their mental and physical well-being coupled with the fear of drowsy driving were strong motivators to change.

One participant continued to work occasional night shifts despite securing a day position. When probing questions were asked as to why, she answered;

“I just feel like by the time we reach adulthood, it's more of a personal decision, a personal choice And we take the chances, you know I hate saying that, but um, you know, you hear other people telling stories about, oh you know, I fell asleep or-or even reading in the paper that a death is because someone fell asleep for a brief, brief, brief moment, it brings to mind oh, I've been in that position. But somehow, I still don't process it as you know what, I got to take action, so I'm not in that position anymore. It's like out of sight, out of mind, once I finish reading and the article is out of my sight, I still need the money and still pays me more. And nothing's happened yet”.

In response to further probing questions, she relayed having worked the night shift as a child alongside her parents and siblings in a factory at night. Being from a large family and new to the United States, it was the only way for the family to get by. She shared loving and fond memories of her family and knew that her parents were doing the best they could. Working nights was a way to provide for the family.

\section{don't know how to fix it}

The 24-hour hospital is here to stay, but so is the pull of the sleep homeostat and the strong need to sleep when sleep deprived. All participants felt that drowsy driving is a big problem and potentially life-threatening for either themselves or 
others. In response to the interview questions below, I received several different responses, although many were followed with a disclaimer that it might not work.

1. Do you have any ideas or suggestions as to what your hospital administrators could do to address this issue?

2. If you had the opportunity to speak to hospital administrators, what would you want them to know?

One participant shared the 'veil of secrecy' that nurses who drive drowsy and fall asleep driving hide behind. She shared;

"Just like when you have addicts and they talk about you know, their recovery and fess up and-and put a face to it. I think that's what, and that's part of the reason why I agreed to do this, is because I was thinking, you know, by saying it out loud, I'm processing it and realize that just like I have my story, there's other people that have this and there's got to be a work around it. And so just sharing the story would be the first step”.

Several participants thought that nurses should be screened for their ability to adapt to the night shift. She couched the statement by adding that it might not be a viable solution in that the more senior nurses had worked nights and might feel that it was unfair to allow some not to work nights.

"It'd be nice if the, if, this is really hard to say but, I guess we could ask management to consider that some people are just not adapted or suitable for the night shift. But I feel that there's a, there's a mentality that you know, if-if one generation has had to do it, then everybody else has to do it as well.” 
This participant took some time off from work after striking a bicyclist in a fall asleep accident. She shared this story with her director and waited for things to change.

"Administrators need to evaluate employees to see if they are a day or night person. “

The director had promised day shift after warning her how hard days would be for a new nurse. He never followed up with a day shift so she resigned, moved out of state, and returned to graduate school in hopes of securing a day position upon confirmation of her advanced degree. While a couple of the participants stated that their managers were open to listening and working with them to alleviate the strain of the night shift, most either were frightened to approach their managers, found them not helpful or just decided that it they needed to put in the hours until they were no longer considered an new graduate.

“No I didn't because I was scared um you know she would, you know think that you know my performance or this would affect my performance and then fire me. I went to school for my associate degree and then I had to ah, then I went for my bachelors and they were paying for, so I, I was scared and I was naive and I didn't know that I could ask for help .I just kind of thought you know I'll just suck it up, you know, I have another nine months to go.”

Unfortunately, many of the participants did not have positive feelings for their employers and did not feel they cared or were interested in the participant's problem with the night shift. 
Several of the participants suggest car-pooling and had actually tried it but found it to be difficult with conflicting scheduled work dates. In addition, they found it difficult when they got off of work on time and had to wait for their carpool-mate who might be running late. Also, people are spread far geographically which poses a challenge to operationalizing carpools.

A suggestion made by several of the participants was to provide sleeping quarters for the nurses. While they did not believe that many would use them after their shift, they did think that napping during breaks was a viable solution. They stated that sleeping even during breaks was against hospital policy and knew of staff that had been terminated for sleeping during work hours.

"I know there are some hospitals have like sleeping areas, so on your break, uh ... what we do, I know, technically you're not supposed to be sleeping on the job, but you know, we are entitled to a break, and on your break, you technically do, you know, you can go talk on the phone, you can go eat, um, so sometimes what I do is on my break, kind of in between, um, right in the middle of my shift, I will go away and, uh, you know, get to go my car and I'll go to sleep for, you know, half an hour, whatever. It’s definitely helpful.”

"It was something that they knew we did but we weren’t really supposed to be doing it. And um, at some of the hospitals we clocked out, at other's you didn't have to clock out for lunch. But they knew that it was like our protected time; we were off the clock. We weren't 
working; so it's now like we were sleeping while we were supposed to be working. But at one hospital I can think of specifically; I won't say the name. But it's here in Los Angeles County um, sleeping is forbidden. If you're on your break; it doesn't matter where you are. And if you want to sleep you have to go to the parking lot and sleep in your car. The problem is the parking lot is about a twenty minute walk from the actual hospital because it's a very huge facility. And so if you wanted to go to your car and come back you couldn’t. They only give you thirty minute breaks and you're not allowed to combine your fifteen minute breaks with your thirty minute lunch break. So you only get thirty minutes for lunch.”

Overall, the idea of sleep rooms, napping, and an evaluation for a nurse's ability to physically and mentally work the night shift were the suggestions that came through many of the interviews.

Support for these suggestions is found in a qualitative study that explored napping on breaks during night shifts. They concluded that 10 out of 13 critical care nurses who napped regularly during breaks reported several benefits to napping, including improved energy, mood and decision-making, and vigilance (Fallis, McMillan, \& Edwards, 2011).

In examining the suggestions by the participants that certain nurses are not well suited for shiftwork, researchers at Vanderbilt obtained DNA samples from participants to determine the extent to which circadian rhythms influenced their adaptation to the shiftwork. They identified the nurses' chronotypes in their human 
circadian genes and predicted who would adapt to nights and who would not (Salisbury, 2011). This type of genetic research is promising in that chronotypes might play a role in how well a nurse adapts to working nights and determining suitability for shiftwork. 


\section{CHAPTER 5}

\section{CONCLUSIONS AND IMPLICATIONS}

This study explored nurses’ perceptions and experiences of falling asleep behind the wheel on the drive home after a worked night shift. By focusing the interviews on the experiences of falling asleep while driving home and eliciting suggestions for mitigating risks of drowsy and/or fall asleep driving after the night shift, this researcher was able to elicit details regarding the registered nurse participants' experiences and their suggestions.

What is clear and well-documented in the literature, are the inherent risks and dangers of driving drowsy and fall asleep accidents. The overwhelming physical urge to fall asleep when a substantial sleep debt has been incurred can only be remedied by sleep. This was validated by the participants as they described the failure of various strategies they used such as loud music, eating, slapping their cheeks, etc. as they attempted to fend off sleep during the drive home. "Putative counter measures to

sleepiness, adopted during continued driving (cold air, use of car radio) are only effective for a short time” (Horne \& Reyner, 1999, p. 289). Sleeping is the only way to combat sleepiness. The research on drowsy and fall asleep driving is clear with regard to the negative impact this behavior has on the safety of the driver and the greater driving public on the roadways. "Sleep related vehicle accidents are not only more common than is generally realized, but are more liable to result in death and serious injury owing to the relatively high speed of the vehicles on impact” (Horne \& Reyner, 1999, p. 289). 
The use of a qualitative descriptive research approach allowed this researcher to present the findings in a way that stayed close to the data with minimal interpretation. Sandelowski (2000), states "There is no mandate to produce anything other than a descriptive summary of an event organized in a way that best contains the data collected and what will be most relevant to the audience for whom it was written” (p. 339). A description of the phenomena is provided in eight themes that emerged from the data and obtained through semi-structured interviews.

There is no prior research study that describes the nurses' experience of fall asleep driving after the night shift. While this served to identify the gap in the literature, prior research studies served to form the basis of the literature review and aid in achieving a comprehensive understanding of the research problem. Conversely, this limitation served to identify the need for this research.

This study contributes to the literature as new information was obtained from the perspective of the participants. The participants felt that it was important to come forward and speak about this issue; to be a part of the change. In order to develop interventions to address this issue, the stories must come from them. As previously stated, there has been no qualitative research to date examining the experience of falling asleep behind the wheel after a worked night. There are no qualitative studies that elicited experiences from nurses in their own words. This study serves as a beginning step to close this gap. The themes that emerged from the participants' interviews provide much needed knowledge as to the experience of the shiftworker who has fallen asleep on the drive home after work. 
One significant finding was the participants' perception of the lack of choice for new graduates with regard to shift selection. All participants with the exception of one discussed that they were not given a choice of shift for their first nursing position. A study of new graduate nurses (West et al., 2007) validates the lack of choice experienced by new graduates as well as their discontent with shiftwork. "It is also commonly perceived that the effects of shift work contribute to the current New Graduate Nurses (NGNs) attrition rate” (West et al., 2007, p.23). Many participants expressed the fact that they had little to no choice but to work the night shift when they were new graduates and in essence, "put in their time" until they had gained enough experience and proficiency and were thereby deemed ready to move to the day shift. As a profession, we need to closely examine why the newest members of the nursing profession are placed on the shift with the least amount of clinical, education, and support resources. The night shift, despite having fewer available resources, was identified by all participants to be the shift that had the greatest amount of teamwork and support. This is an interesting finding that raises concerns regarding nurse staffing across shifts. If strong teamwork is an essential component of patient safety, that component should remain consistent 24 hours per day

Participants also underscored their discomfort and reluctance with speaking to their nursing leaders regarding their struggle with shiftwork. Some of the participants recounted unpleasant exchanges with their nurse leaders regarding their difficulty with shiftwork and others stated that when they did speak with their nurse leaders, little if anything was accomplished. This information also raises a number of questions and concerns related to nursing administration. It is possible that nurse managers are not 
aware of the current literature related to the negative effect of shiftwork on their staff. The fact that the participants were uncomfortable speaking with their nurse managers questions the level of trust between the mangers and their staff.

The nurses who participated in this study were deeply concerned for their safety and the safety of others on their drive home after their scheduled shift. Participants described the experience of drowsy driving and falling asleep behind the wheel as frightening, terrifying, and scary. They discussed those first few moments of fright and disbelief when they realized they had arrived home without recollection of the parts of the drive or had passed their exit and had no memory as to how they had arrived where they were. Many nurses continue shiftwork despite a foreboding fear of involvement in a vehicular accident as well as persistent unpleasant physical and psychological effects of shiftwork. They fail to see any viable alternative options. Some participants chose not to share their experiences with family and friends as they did not wish to frighten them or cause them to worry. This illustrates the lack of congruence that seems to exist between knowing the potential negative outcomes of this behavior and changing their behavior. .

\section{Methodological Implications}

For this study, the researcher identified the lack of existing qualitative descriptive research of nurses' experiences falling asleep on the drive home after a scheduled night shift. While there are multiple studies that have examined drowsy and fall asleep driving, they are primarily from a quantitative point of view. In addition, there are no studies that include suggestions for mitigation of the risk in the voice of nurses who themselves have experienced the phenomenon. This study provides a 
foundation to begin to understand structures and processes that might affect implementation of interventions to mitigate the risk of drowsy or fall asleep driving by nurse shiftworkers. Initiatives or interventions that are a good fit with existing organizational goals and staff preferences are more likely to be adapted. This research adds knowledge from the perspective of the nurse that may serve to facilitate effective implementation, test new approaches and determine causal relationships between interventions and their impact. For example, in this study, participants suggested that car-pooling might be an alternative to driving drowsy and fall asleep driving. However, the participants were quick to cite the reasons that it was not operationally feasible.

It was important to provide a description of the phenomenon that was lacking in the existing body of literature as well as suggestions from those who have experienced the phenomenon in order to heighten awareness of the phenomenon and also to provide an initial review of the feasibility of interventions. This study augments the existing literature on nurses and fatigue in that the focus is on nurse safety after the work shift is completed. Many of the existing studies of nurse shiftworkers focus on the effect of nurse fatigue during worked hours on patient safety.

Selection of a qualitative descriptive research methodology allowed the researcher to present the data in a way that holds true to the qualitative description by remaining close to the data. For all of the women who participated in this study, the use of in-depth semi-structured interviews gave the participants the opportunity to discuss the phenomena using their own voice. Most importantly, the study gave the participants a chance to be heard. 
In the discussion of the findings in Chapter 4, the voice of the participant is commonly used in juxtaposition with comments from the researcher. Paraphrasing was avoided and actual quoted text was utilized to provide the reader with the voice of the participant. The interview process afforded the researcher the opportunity to gather extensive and comprehensive data that would have otherwise been inaccessible.

The qualitative methodology allowed for in-depth information and reasons or explanations as to why the participants worked the night shift, a comprehensive account of their experience with fall asleep driving, and their suggestions for correction of the phenomena. During the interview, the participants were asked to reconstruct the events of a time when they fell asleep behind the wheel. They were asked to describe the event as it unfolded. This reconstruction of an event could not have been accomplished without in-depth interviews.

A strength of the use of qualitative description lies in the fact that there are no theoretical strings attached, thereby allowing the analysis to remain close to both the data and the participant’s point of view (Neergaard et al., 2009; Sandelowski, 2000).. As one participant stated,

"Just like when you have addicts and they talk about you know, their recovery and fess up and-and put a face to it. I think that's what, and that's part of the reason why I agreed to do this, is because I was thinking, you know, by saying it out loud, I'm processing it and realize that just like I have my story, there's other people that have this and there's got to be a work around it. And so just sharing the story would be the first step." 


\section{Researcher Qualifications}

The researcher has extensive experience doing shiftwork, has personally experienced a fall-asleep accident after a worked night shift, and has twenty years of experience in nursing leadership. Disclosure of this information with the participants prior to the beginning of the interview served to diminish the fear of being judged or dismissed. This was critical in facilitation of the interview situation. While the researcher's first-hand experience was invaluable, it was important to remain open to new learning and revelations during the study process to allow for a growth of knowledge.

The researcher's background experience with the phenomena as noted above may be alternately viewed as a limitation of the study. The awareness of prior understanding was consciously noted by the researcher and served to minimize that risk. In addition, the data analysis was validated by Drs. Dufault and Ferszt.

Driving when drowsy and/or falling asleep behind the wheel is viewed as “impaired driving. “ According to Kuhar, (SafeNY, 2013, para. 8), “The state of drowsiness itself is a significant impairment while driving and has been shown in several studies to be as dangerous as driving drunk. In driving performance testing, 17 hours of sustained wakefulness was equivalent to driving with a blood alcohol content of $0.05 \% . ”$

Those who knowingly drive drowsy or fall asleep driving are only too aware of the feelings of impairment and the associated stigma. The researcher maintained an approach of appreciative inquiry along with a non-judgmental attitude towards the participants and their responses during the interviews. The process of Appreciative 
Inquiry employs a particular way of asking questions that encourage positive thinking and employee-to-employee interaction. The researcher was attuned to avoidance of any subtle stigmatizing attitude or expressions during the interview process knowing that this would limit the level of comfort in sharing on the part of the participant. .

As a final and most important qualification, this researcher espouses the virtues of humility, patience, and perseverance. In the acquisition of new skills, it is important to call upon these virtues in facilitate movement to completion of the study. These qualities are the key to the success for novice researcher. Humility is critical in asking for guidance and support from the knowledge and content experts. It is critical in the feelings of discomfort that accompany the practice of a new skill, e.g., interviewing participants.

Patience as a qualification was important in that it allowed the researcher to be immersed in the data and not resort to primary closure in the process of analysis. The emergence of themes takes time and cannot be rushed. The virtue and capacity for perseverance served to propel the study forward and maintain the energy and momentum.

Despite a multitude of competing priorities, the researcher internalized the importance of the study and maintained a sense of urgency to the work at hand. The researcher was fully committed to the aim of the research study and has personal and professional interest in the topic

\section{Implications for Nursing Research}

This study begets a priority for research to further knowledge development regarding drowsy/fall asleep driving. "Nursing exists to provide high-quality nursing 
care to individuals in need of health-promoting, health-sustaining, and health-restoring strategies” (Webb, 2013, p. 108). While Dr. Webb’s statement infers that those “individuals” are patients, certainly the profession of nursing has a responsibility to care for the profession and its members as well.

In order to be integral in the development of nursing knowledge, a research study must seek to answer questions that are considered significant and relevant. This research study is significant to front-line staff nurses, nursing leaders and hospital administrators. It is posited that this study will be utilized by nurse scientists to identify interventions that mitigate the risk of drowsy/fall asleep driving in nurse shiftworkers that could form the basis for a research agenda.

Priorities for nursing research were identified via a review of the literature along with interviews with the participants. Potential areas for future research include:

1.) Conduct research to evaluate the effectiveness of restorative napping. While restorative napping has had promising results in some research studies, organizational barriers exist in the form of policies or unwritten policies. In a study of 13 critical care nurses who completed semistructured interviews exploring napping “...participants identified a number of personal, safety, and patient safety factors that support the need for a restorative nap during the night shift” (McCann, 2008, para. 3). Research as to the effect of a nap during the night shift on the nurses’ ability to drive home safely after work should be examined. As mentioned earlier, organizational barriers and negative attitudes towards "sleeping on the job” must be challenged with rigorous 
research and the development of best and safe practices to effect safe driving practices.

2.) Clinical Research related to screening for physical and mental ability to work the shift.

Many of the participants stated they believed that they were not physically able to work the night shift. They offered anecdotal evidence that they were unlike other nurses who appeared unaffected by shiftwork. In fact, they were perplexed by their own inability to adapt to shiftwork. According to a study by Schmidt, et al. (2009) examining sleep pressure, which increases with the length of time an individual is awake, certain individuals were identified as more susceptible to sleep pressure while others had greater stamina against the build-up of sleep pressure. Individuals who identify themselves as "early birds" had greater difficulty fending off sleep as they sleep pressure increased. Failing to take into account the individual differences among nurses’ physiological ability for shiftwork and reliance on prescribed staffing patterns and must be examined.

Research can be used to influence policy to mitigate the risk of driving drowsy/falling asleep after the night shift. Use the voices of the shiftworkers in this study as a basis of urging the development of policies addressing the risk of drowsy/fall asleep driving after the night shift. 
This research can serve to heighten awareness about nurses struggling to stay awake while driving home. The addition of this knowledge to the literature can serve as a catalyst in impacting change.

A more immediate priority is the focus on the issue at hand - nurses falling asleep behind the wheel on their commute home after the night shift. While further research is necessary, there is a need for immediate attention to this safety issue. Nurses must speak up and share their stories with colleagues and nursing leaders. The issue of fatigue is gaining the attention of regulatory agencies in terms of its effect on patient safety. The results of this study show that in addition to patient safety, nurse safety is at also at risk.

In discussions with registered nurses (in addition to the study participants), drowsy driving or fall asleep driving after the night shift is a ubiquitous phenomenon. The practice continues every morning as nurses complete their night shift and drive home. This research not only provides a significant contribution of knowledge to the nursing profession, but also acts as a springboard for further research of the efficacy of the participants suggested interventions with the goal of decreasing the potential danger and risk this phenomenon brings.

\section{Implications for Nursing Administration}

The intended audience for this study is nurses, nursing leaders, and hospital administrators. It is hoped that the results of this study will serve as a "wake-up call” if you will, to the need for safe options. For the most part, the participants were either frightened to approach their nurse managers or did not consider doing so. Nursing leadership should be required to attend training in sleep hygiene, and sleep physiology 
so that they can optimize scheduling to ensure adequate rest between shifts and be alert to nurses who are leaving work and are in danger of drowsy and/or fall asleep driving. Sleep is a serious issue that needs to be treated as a priority for the well-being of employees.

Nursing leadership and the shiftworkers share accountability to ensure options for nurses who struggle to stay awake during the drive home after a worked night shift. Nursing leaders and hospital administrators must review the evidence and consider policies and/or procedures to identify those individuals who are physically unable to engage in shiftwork without physical detriment. We have no screening process for those who are asked to work the night shift. This bears further investigation.

Shiftworkers should also undergo training for sleep hygiene. Sleep hygiene is a variety of practices that are necessary to have normal, quality sleep. In addition, staffing policies should be in place and have a provision for offering a place to sleep or transportation home for a sleep-deprived worker. The researcher hopes that by sharing the words of the participants, nursing leaders will be moved to action. Often research is presented in dense data in the form of spreadsheets that are categorized and calculated. This study offers the reader a story. A story told in the voices of nurses who hope that nursing leaders and nursing researchers are paying attention and will take action. 


\section{TABLES}

Table 3

Qualitative Description-Major Tenets

\begin{tabular}{|l|l|}
\hline Design Issues & \multicolumn{1}{|c|}{ Design Specifics } \\
\hline Philosophy & $\begin{array}{l}\text { General tenets of naturalistic inquiry apply. } \\
\text { Pragmatic approach } \\
\text { May have overtones of other qualitative orientations (eg. } \\
\text { grounded theory, ethnography, phenomenology) }\end{array}$ \\
\hline Sample & $\begin{array}{l}\text { Purposeful Sampling } \\
\text { Maximum Variation Sampling is especially pertinent }\end{array}$ \\
\hline Data Collection & $\begin{array}{l}\text { Minimally to moderately structured, open ended interviews with } \\
\text { individuals or focus groups } \\
\text { Researchers are interested in the Who, What , Where and Why of } \\
\text { the experience } \\
\text { Observation of specific occurrences } \\
\text { Review of documents or other pertinent materials }\end{array}$ \\
\hline Analysis & $\begin{array}{l}\text { Qualitative content analysis using modifiable coding systems that } \\
\text { correspond to the data collected } \\
\text { Quasi-statistical analysis methods using numbers to summarize } \\
\text { data with descriptive statistics } \\
\text { Stay close to the data-low level interpretation (if using } \\
\text { qualitative software such as NVivo, the use of “Invivocoding” } \\
\text { procedures works well here. } \\
\text { Goal of the anlaysis strategy is to understand the latent variable } \\
\text { (useful for concept classification and instrument development) }\end{array}$ \\
\hline Outcomes & $\begin{array}{l}\text { Straight description of the data organized in a way that “fits" the } \\
\text { data (eg.chronologically by topic, by prevalence, etc.) }\end{array}$ \\
\hline
\end{tabular}

Note. In Sandelowski, 2000 and Sullivan-Bolyai, Bova, \& Harper, 2005. 
Table 4

Characteristics of the Responsive Interviewing Model

\begin{tabular}{|c|c|}
\hline \multicolumn{2}{|r|}{ Characteristics of the Responsive Interviewing Model } \\
\hline 1. & $\begin{array}{l}\text { Interviewing is about obtaining interviewee's interpretations of their } \\
\text { experiences and their understandings of the world in which they live and work. }\end{array}$ \\
\hline 2. & $\begin{array}{l}\text { The personality, style, and beliefs of the interviewer matter, Interviewing is an } \\
\text { exchange, not a one-way street; the relationship between the interviewer and } \\
\text { interviewee is meaningful, even if temporary. Because the interviewer } \\
\text { contributes actively to the conversation, he or she must be aware of his or her } \\
\text { own opinions, experiences, cultural definitions, and even prejudices. }\end{array}$ \\
\hline 3. & $\begin{array}{l}\text { Because responsive interviews depend on a personal relationship between } \\
\text { interviewer and interviewee and because that relationship may result in the } \\
\text { exchange of private information, or information dangerous to the interviewee. } \\
\text { Moreover, the interviewer is imposing on the time, energy, emotion, and } \\
\text { creativity of the interviewee and therefore owes loyalty and protection in } \\
\text { return. }\end{array}$ \\
\hline 4. & $\begin{array}{l}\text { Interviewers should not impose their views on interviewees. They should ask } \\
\text { broad enough questions to avoid limiting what interviewees can answer, listen } \\
\text { to what interviewees tell them, and modify their questions to explore what they } \\
\text { are hearing, not what they thought before they began the interview. }\end{array}$ \\
\hline 5. & $\begin{array}{l}\text { Responsive interviewing design is flexible and adaptive. Because the } \\
\text { interviewer must listen intently and follow up insights and new points furing } \\
\text { the interview, the interviewer must be able to change course based on what he }\end{array}$ \\
\hline
\end{tabular}




\begin{tabular}{|l|l|}
\hline or she learns. Interviews may need to change whom they plan to talk to or \\
where they plan to conduct an interview as they find out more about their \\
research questions.
\end{tabular}

Note. Characteristics of the Responsive Interviewing Model. Adapted from

Qualitative Interviewing: The Art of Hearing Data (p. 36) 2d ed., by H. J.

Rubin and I. S. Rubin, 2005, Thousand Oaks: Sage Publications. Copyright 2007 by the National Academy of Sciences. 
Table 5

Night shifts better for new grads

\begin{tabular}{|c|c|c|}
\hline Meaningful Units & $\begin{array}{c}\text { Condensed } \\
\text { Meaning Units }\end{array}$ & Code \\
\hline $\begin{array}{l}\text { And I'm a new grad, yeah, and I figured } \\
\text { - at first I figured it would probably be } \\
\text { an easier transition going from student to } \\
\text { a new nurse. }\end{array}$ & $\begin{array}{l}\text { Easier transition } \\
\text { going from student } \\
\text { to a new nurse }\end{array}$ & \multirow{6}{*}{$\begin{array}{l}\text { Nights Shifts Better } \\
\text { for New Grads }\end{array}$} \\
\hline $\begin{array}{l}\text { Yes, it's not by choice I can tell you that. } \\
\text { So they start us all off on nights in } \\
\text { precept. And then we have to do at least } \\
\text { a year on nights before we can transition } \\
\text { to days. So my year is coming up this } \\
\text { fall. }\end{array}$ & $\begin{array}{l}\text { Not by choice I } \\
\text { can tell you that. }\end{array}$ & \\
\hline $\begin{array}{l}\text { Yeah, I worked for about a year, night } \\
\text { shift. We had to do that um as a new } \\
\text { grad. So it was more like not an option } \\
\text { for me, I didn't choose. }\end{array}$ & $\begin{array}{l}\text { Not an option for } \\
\text { me, I didn’t } \\
\text { choose. }\end{array}$ & \\
\hline $\begin{array}{l}\text { It's a little different during the day. I just } \\
\text {... I think also being like a newer nurse I } \\
\text { will ... I have all this work, and my } \\
\text { charge nurse I could go to and they } \\
\text { would help me. Nightshift works as a } \\
\text { team. }\end{array}$ & $\begin{array}{l}\text { Team support on } \\
\text { nights }\end{array}$ & \\
\hline $\begin{array}{l}\text { Because I was a new graduate at the time } \\
\text { and they made us all start on night shift. } \\
\text { you know people with seniority get the } \\
\text { day shift. }\end{array}$ & $\begin{array}{l}\text { They made us all } \\
\text { start on nights. } \\
\text { People with } \\
\text { seniority get the } \\
\text { day shift. }\end{array}$ & \\
\hline $\begin{array}{l}\text { But as a new graduate, um, the workload } \\
\text { is crazy on days, so I thought ... I felt }\end{array}$ & $\begin{array}{l}\text { Felt I could do a } \\
\text { better job working } \\
\text { nightshift. }\end{array}$ & \\
\hline
\end{tabular}




\begin{tabular}{|l|l|l|}
\hline that I could do a better job working & & \\
nightshift. I could actually have time to & & \\
read the HPs, learn about my patients, & & \\
look up patient histories, look up diseases & & \\
that I didn't know. & & \\
\hline
\end{tabular}


Table 6

Struggling to stay awake

\begin{tabular}{|c|c|c|}
\hline Meaningful Units & $\begin{array}{c}\text { Condensed } \\
\text { Meaning Units } \\
\end{array}$ & Code \\
\hline I had sleep paralysis & Sleep paralysis & \multirow{6}{*}{$\begin{array}{l}\text { Struggling to Stay } \\
\text { Awake }\end{array}$} \\
\hline $\begin{array}{l}\text { I was holding my steering wheel with } \\
\text { two hands like this and I couldn't open } \\
\text { my eyes sometimes. }\end{array}$ & $\begin{array}{l}\text { Couldn’t open my } \\
\text { eyes }\end{array}$ & \\
\hline $\begin{array}{l}\text { about halfway into my driving I-I would } \\
\text { do the nod, do the nod and probably quite } \\
\text { a lot of times just doing the nod }\end{array}$ & Just doing the nod & \\
\hline $\begin{array}{l}\text { I think I must have slept at least ten times } \\
\text { during my entire journey back home. I } \\
\text { think; at least if not more. }\end{array}$ & $\begin{array}{l}\text { Slept during my } \\
\text { journey back home }\end{array}$ & \\
\hline $\begin{array}{l}\text { I went from first lane to the fourth lane } \\
\text { and hit the sidewalk and hit a bicyclist. } \\
\text { Woke up to a noise. I told him "I think I } \\
\text { fell asleep” }\end{array}$ & $\begin{array}{l}\text { Woke up to a noise } \\
\text { after crossing three } \\
\text { lanes - had hit a } \\
\text { bicyclist. }\end{array}$ & \\
\hline $\begin{array}{l}\text { I have a lot of stories; I can remember } \\
\text { falling asleep all the time (while driving). }\end{array}$ & $\begin{array}{l}\text { Falling asleep all } \\
\text { the time }\end{array}$ & \\
\hline
\end{tabular}


Table 7

It's Scary

\begin{tabular}{|c|c|c|}
\hline Meaningful Units & $\begin{array}{c}\text { Condensed } \\
\text { Meaning Units } \\
\end{array}$ & Code \\
\hline $\begin{array}{l}\text { “...it was just scary to me to know that } \\
\text { I'm actually falling asleep driving." }\end{array}$ & $\begin{array}{l}\text { Scary falling } \\
\text { asleep driving }\end{array}$ & \multirow{6}{*}{ It's Scary } \\
\hline $\begin{array}{l}\text { I was so tired but terrified to go to sleep } \\
\text { because of the sleep paralysis. }\end{array}$ & $\begin{array}{l}\text { Terrified because } \\
\text { of the sleep } \\
\text { paralysis }\end{array}$ & \\
\hline $\begin{array}{l}\text { "I've heard of a lot of things have } \\
\text { happened to people. Like some people } \\
\text { they'll be like one of my friends her, um, } \\
\text { her fiancée was driving home and he } \\
\text { actually fell off a cliff from falling asleep } \\
\text { and, you know, he passed away.” }\end{array}$ & $\begin{array}{l}\text { Heard a lot of } \\
\text { things have } \\
\text { happened to } \\
\text { people }\end{array}$ & \\
\hline $\begin{array}{l}\text { “I'm swerving or whatever I'm doing } \\
\text { between those three or four seconds of } \\
\text { what I would call a sleep I'd wake up and } \\
\text { I - my heart was just adrenaline rush. } \\
\text { I'm like don't do that, but I couldn't help } \\
\text { it because I'm so tired” }\end{array}$ & $\begin{array}{l}\text { My heart was just } \\
\text { an adrenaline rush }\end{array}$ & \\
\hline $\begin{array}{l}\text { "I want you to be alive, Mommy, so do } \\
\text { the dayshift.” “...this isn't really that } \\
\text { safe, and I have to figure out a different } \\
\text { plan.” }\end{array}$ & $\begin{array}{l}\text { I want you to be } \\
\text { alive Mommy }\end{array}$ & \\
\hline $\begin{array}{l}\text { “...one time that was really scary was } \\
\text { I'm exiting my freeway off-ramp, I’m } \\
\text { almost home, half a mile from home, and } \\
\text { the off-ramp curves a little bit, and I just } \\
\text { overshot the curving part, and I bumped } \\
\text { up the curb and back down.” }\end{array}$ & $\begin{array}{l}\text { Really scary, } \\
\text { bumped up against } \\
\text { the curb }\end{array}$ & \\
\hline
\end{tabular}




\begin{tabular}{|l|l|l|}
\hline $\begin{array}{l}\text { “And when I swayed and I know I'm } \\
\text { going } 60 \text { miles an hour, } 70 \text { miles an hour, } \\
\text { it's scary.” }\end{array}$ & $\begin{array}{l}\text { I'm going } 60 \text { or } 70 \\
\text { miles an hour...it's } \\
\text { scary. }\end{array}$ & \\
\hline $\begin{array}{l}\text { Feel panicked and jolted awake. But then } \\
\text { oddly enough, you feel still sleepy, for a } \\
\text { little, you know. }\end{array}$ & Feel panicked & \\
\hline
\end{tabular}


Table 8

Just need to get home

\begin{tabular}{|c|c|c|}
\hline Meaningful Units & $\begin{array}{c}\text { Condensed } \\
\text { Meaning Units }\end{array}$ & Code \\
\hline $\begin{array}{l}\text { I don’t even remember how I got home } \\
\text { but I know that I passed some red lights. I } \\
\text { heard cars honking at me, but I was so } \\
\text { sleepy that I didn’t even react to it. It } \\
\text { didn’t even like scare me It was just, “I } \\
\text { need to get home” }\end{array}$ & $\begin{array}{l}\text { Ran through red } \\
\text { lights-just wanted } \\
\text { to get home. }\end{array}$ & \multirow{5}{*}{$\begin{array}{l}\text { Just Need to get } \\
\text { home }\end{array}$} \\
\hline $\begin{array}{l}\text { I'd drive fast going home and I mean, } \\
\text { have have a I hate to say it, I mean good } \\
\text { thing no cops have ever really pulled me } \\
\text { over, just to get home and I just wanted } \\
\text { to be home. I think that was my-my-my } \\
\text { focus was just get home and so I can } \\
\text { sleep. }\end{array}$ & & \\
\hline $\begin{array}{l}\text { I was like maybe ten minutes or five } \\
\text { minutes away from home. I just couldn’t } \\
\text { reach home. }\end{array}$ & & \\
\hline $\begin{array}{l}\text { You're sitting at a light and, uh, you're } \\
\text { starting to doze off your head, your, you } \\
\text { know, kind of nods down. And you } \\
\text { think, “Oh my gosh, I'm so close to being } \\
\text { home. I can’t fall asleep.” }\end{array}$ & & \\
\hline $\begin{array}{l}\text { There were times when I would pull into } \\
\text { my driveway and be so exhausted that I } \\
\text { couldn't even make it into the house. } \\
\text { Um, so I'd fall asleep for an hour and a } \\
\text { half, two hours sometimes, and wake up, }\end{array}$ & & \\
\hline
\end{tabular}




\begin{tabular}{|l|l|l|}
\hline and be like, “Oh, I'm asleep.” & & \\
\hline there are times where I got home and I & & \\
had to sleep in the car I couldn't even get & & \\
up to go in the house & & \\
\hline
\end{tabular}


Table 9

Not a Night Person

\begin{tabular}{|c|c|c|}
\hline Meaningful Units & Condensed Units & Theme \\
\hline $\begin{array}{l}\text { But working nights, um, you know, the } \\
\text { next day after, two in a row, three in a } \\
\text { row, I'm just wiped out. I'll sleep during } \\
\text { the day and then sleep again during the } \\
\text { night, and I know that my body is more } \\
\text { tired, }\end{array}$ & $\begin{array}{l}\text { My body is more } \\
\text { tired }\end{array}$ & \multirow{5}{*}{ Not a night person } \\
\hline $\begin{array}{l}\text { I'm not a night person. I realized after } \\
\text { working night shift I'm not a night person } \\
\text { at all. }\end{array}$ & $\begin{array}{l}\text { I'm not a night } \\
\text { person at all }\end{array}$ & \\
\hline $\begin{array}{l}\text { I just think that I mean for me it’s not for } \\
\text { me. I don't know if it's because I haven’t } \\
\text { gotten used to it, but I think I have tried a } \\
\text { lot of different ways to get around it. }\end{array}$ & $\begin{array}{l}\text { It's not for me... I } \\
\text { have tried a lot of } \\
\text { ways to get around } \\
\text { it }\end{array}$ & \\
\hline $\begin{array}{l}\text { I strongly believe that I'm a day person } \\
\text { and I think this has happened like } \\
\text { because I'm a day person, I'm not a night } \\
\text { person. }\end{array}$ & $\begin{array}{l}\text { I'm a day person, } \\
\text { not a night person }\end{array}$ & \\
\hline $\begin{array}{l}\text { I feel like I am one of the people who is } \\
\text { more tired in the morning. I feel like } \\
\text { everyone else when they leave work it } \\
\text { doesn't look like... you know some } \\
\text { people even go out to breakfast after } \\
\text { work with each other. I can't do that. } \\
\text { They go out and they have like Mimosa's } \\
\text { and they have breakfast on the } \\
\text { waterfront. And they... I always get } \\
\text { invited and I’ve never gone in the year }\end{array}$ & $\begin{array}{l}\text { Some people can } \\
\text { go out after } \\
\text { working nights, I } \\
\text { can't. }\end{array}$ & \\
\hline
\end{tabular}




\begin{tabular}{|c|c|c|}
\hline $\begin{array}{l}\text { I've been there because I just I wouldn't } \\
\text { be able to drive home afterwards. }\end{array}$ & & \\
\hline $\begin{array}{l}\text { Because I know there's some - some } \\
\text { nurses that I work with and, you know, } \\
\text { they've been a very long time nights they } \\
\text { drive extremely far and they’re not going } \\
\text { straight to bed, they're just going straight } \\
\text { to an area to pick up their children and - } \\
\text { and, you know, I honestly don't know } \\
\text { how they make it. }\end{array}$ & $\begin{array}{l}\text { Some nurses I } \\
\text { work with they } \\
\text { drive far and don't } \\
\text { go right to bed }\end{array}$ & \\
\hline
\end{tabular}


Table 10

Feeling Awful

\begin{tabular}{|c|c|c|}
\hline Meaningful Units & $\begin{array}{c}\text { Condensed } \\
\text { Meaning Units }\end{array}$ & Code \\
\hline $\begin{array}{l}\text { I'm like dead for a day and a half after } \\
\text { that but then I go back to my day cycle } \\
\text { but then by the time I get used to it I go } \\
\text { back to the nights and it's just like I don't } \\
\text { feel refreshed after I go to sleep. My } \\
\text { stomach is always swollen, I have } \\
\text { digestion problems }\end{array}$ & & \\
\hline $\begin{array}{l}\text { But when I mean zombie there would be } \\
\text { days when I was just - it’s just so routine } \\
\text { that I would just go to bed, wake up, go } \\
\text { to work, do the night shift, what - drive } \\
\text { home, go to work and-and I would just, } \\
\text { my mind - physically I probably looked } \\
\text { ugly, bags under my eyes, mentally I } \\
\text { tried to be prepared like, you know, I } \\
\text { have to-to redo my cycle, but it was just I } \\
\text { felt fatigued I guess you can say. }\end{array}$ & & Feeling awful \\
\hline $\begin{array}{l}\text { "Physically, emotionally, mentally I } \\
\text { would feel so like, I don’t want to say } \\
\text { stressed, but I just feel like I couldn’t do } \\
\text { things.” }\end{array}$ & & \\
\hline $\begin{array}{l}\text { I couldn't take care of myself, I couldn't, } \\
\text { I could barely eat. I could, I was just } \\
\text { very irritated most of the time you know? } \\
\text { You just feel like you're not, you're not } \\
\text { your best you know you're not, you're not } \\
\text { doing the best you can because you're }\end{array}$ & & \\
\hline
\end{tabular}




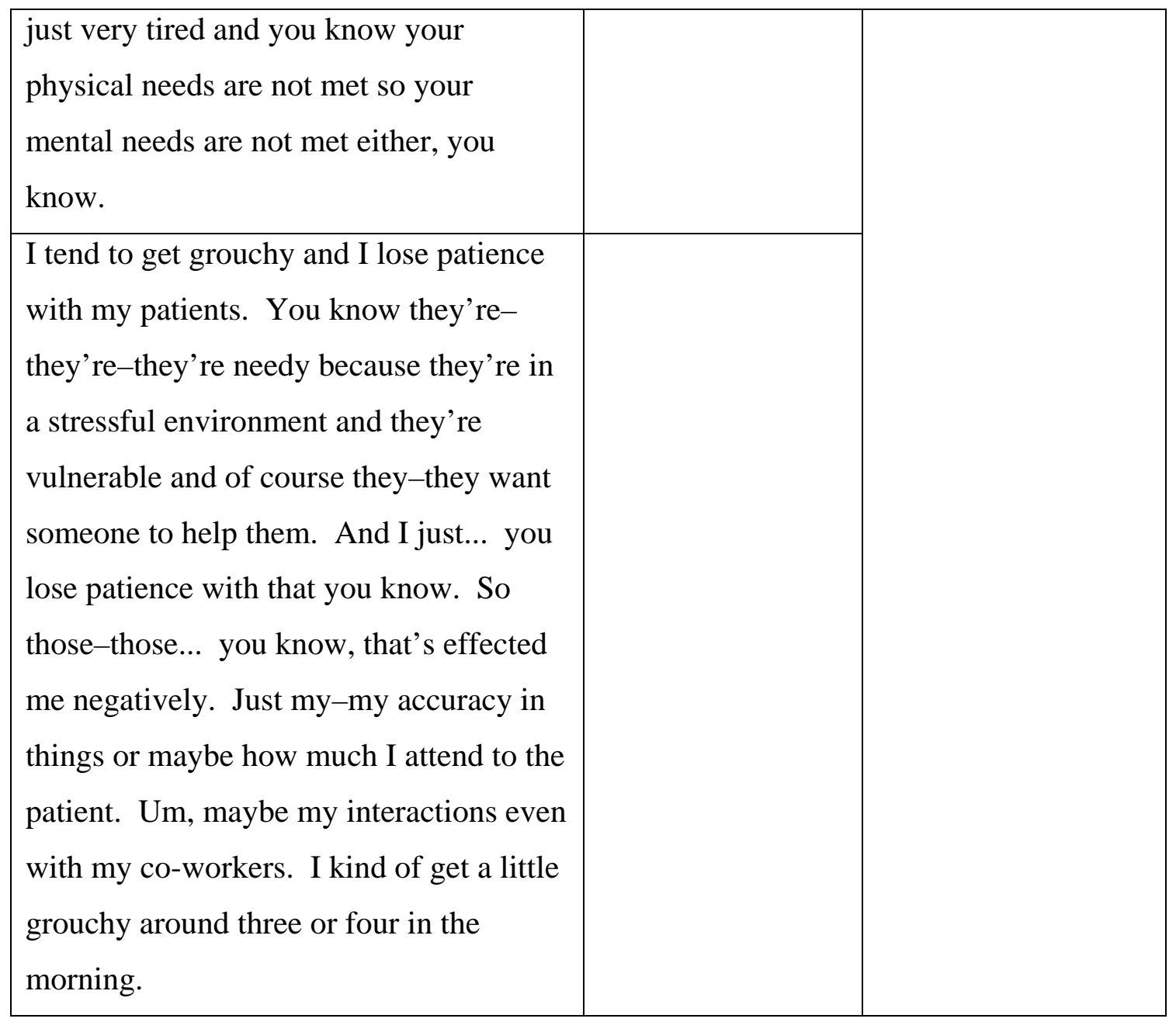


Table 11

Don't know how to fix it

\begin{tabular}{|c|c|c|}
\hline Meaningful Units & $\begin{array}{c}\text { Condensed } \\
\text { Meaning Units } \\
\end{array}$ & Code \\
\hline $\begin{array}{l}\text { "After my accident I had to take time off } \\
\text { of work"(feared going back to the night } \\
\text { shift) }\end{array}$ & $\begin{array}{l}\text { Had to take time } \\
\text { off of work }\end{array}$ & \multirow{6}{*}{$\begin{array}{l}\text { Don't know how to } \\
\text { fix it. }\end{array}$} \\
\hline $\begin{array}{l}\text { "Moved out of state for to get a day shift } \\
\text { job" }\end{array}$ & $\begin{array}{l}\text { Had to move to get } \\
\text { a day job }\end{array}$ & \\
\hline $\begin{array}{l}\text { Provide sleep rooms in the hospital a } \\
\text { good idea, although many won't use } \\
\text { them due to family obligations to return } \\
\text { home }\end{array}$ & $\begin{array}{l}\text { Provide sleep } \\
\text { rooms-although } \\
\text { many won't use } \\
\text { them }\end{array}$ & \\
\hline $\begin{array}{l}\text { Tried carpooling-- a hassle to think } \\
\text { about, “Oh, I need to hurry. Like are you } \\
\text { coming to my house, or I'm going there.” } \\
\text { And then what if the report takes long, or } \\
\text { "You get out at 8:00, oh, I'm sitting here } \\
\text { at 7:30, I should've ... I could've been } \\
\text { home by 8:00, 8-something.” }\end{array}$ & $\begin{array}{l}\text { Carpooling might } \\
\text { help but it is a } \\
\text { hassle }\end{array}$ & \\
\hline $\begin{array}{l}\text { "I know at certain hospitals they allow } \\
\text { nurses to take an hour lunch, and actually } \\
\text { allow them to sleep during that period of } \\
\text { time. Uh, at our hospital we're not } \\
\text { allowed to do that" }\end{array}$ & $\begin{array}{l}\text { Sleep during } \\
\text { breaks }\end{array}$ & \\
\hline $\begin{array}{l}\text { “....the reason why I agreed to do this, is } \\
\text { because I was thinking, you know, by } \\
\text { saying it out loud, I'm processing it and } \\
\text { realize that just like I have my story, } \\
\text { there’s other people that have this and } \\
\text { there’s got to be a work around it. And }\end{array}$ & $\begin{array}{l}\text { We need to give a } \\
\text { voice to this and } \\
\text { share. We are a } 24 \\
\text { hour society. }\end{array}$ & \\
\hline
\end{tabular}




\begin{tabular}{|l|l|l|}
\hline $\begin{array}{l}\text { so just sharing the story would be the first } \\
\text { step. } \\
\text { Um, because we're } 24 \text { hour society, } \\
\text { we're demanding all of the vocations to } \\
\text { have night shift accessibility, um, and I } \\
\text { was thinking, so this goes beyond this as } \\
\text { health care workers. }\end{array}$ & \\
\hline $\begin{array}{l}\text { I wish there was public transportation I } \\
\text { could take; obviously the hospital can't } \\
\text { do that. }\end{array}$ & $\begin{array}{l}\text { Wish there was } \\
\text { public } \\
\text { I guess we could ask management to } \\
\text { consider that some people are just not } \\
\text { adapted or suitable for the night shift. }\end{array}$ & $\begin{array}{l}\text { Some people just } \\
\text { aren't suited for } \\
\text { the night shift }\end{array}$ \\
\hline
\end{tabular}




\section{FIGURES}

Figure 1

Inductive and deductive Content Analysis Process

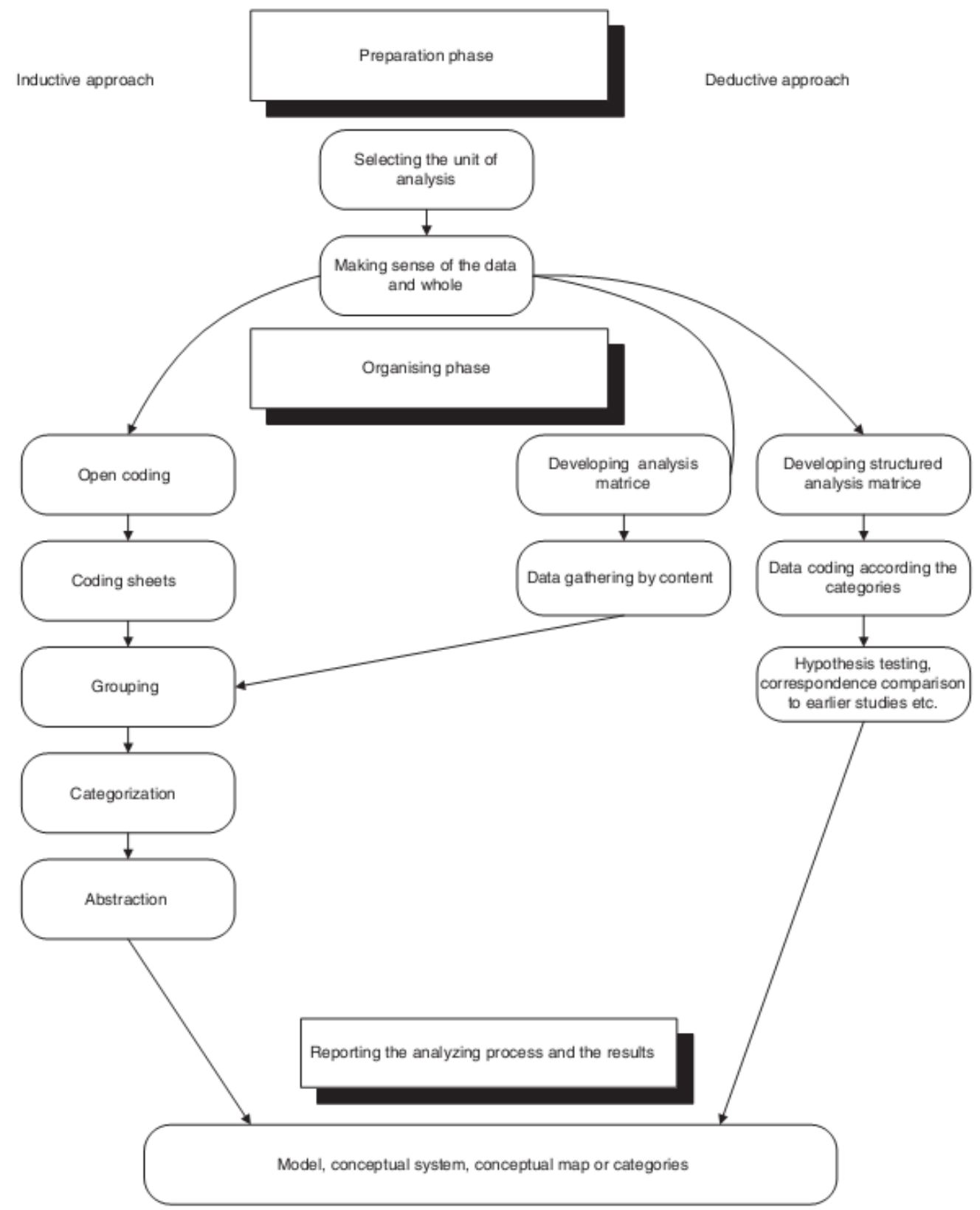

Note. From “The Qualitative Content Analysis Process” by Elo, S. \& Kyngas, H.

(2008). In Journal of Advanced Nursing 62(1) p.110. 


\section{APPENDICES}

Appendix A - Letter of invitation to Participate

Invitation to Participate

\section{Re: Research Study: A Qualitative Descriptive study to explore the experiences of night shift nurses who fall asleep behind the wheel on the commute home after a worked night shift.}

Dear Night Shift RN, My name is Shirley Sargent, I am currently working on a research study in nursing at the University of Rhode Island. My proposed study for my dissertation aims to explore the experiences of nurses who have fallen asleep behind the wheel on the commute home after a worked night shift. This study aims to answer the question: What is the experience of falling asleep behind the wheel on the drive home from a worked night shift? My hope is to illuminate the issue of night nurses and drowsy driving and shift work. This researcher hopes that the study will benefit night shift nurses and improve standards in this area. I would like to invite all staff nurses who have fallen asleep at the wheel driving home from a worked night shift. Anyone who chooses to take part will be requested to sign a consent form to partake in a 45-60 minute audio-taped interview which will be held at a time convenient to you and in a private meeting area or conference room. Be advised that participation is voluntary and that you have the right to withdraw from the study at any time and any data obtained will be removed from the database. Any information gathered from this study will remain confidential. Thank you for taking the time to read this letter. Should you wish to take part in this study, or have any further questions prior to making a decision, please feel free to contact me at 617-279-3119 or ssargent81@gmail.com. If you do decide to participate, please contact me either via phone or email.

A gift card to Starbuck in the amount of $\$ 25.00$ will be provided for each participant. Kind regards,

Shirley Sargent PhD (c), RN 
Appendix B

Interview Guide

\section{INTERVIEW GUIDE}

1. How long have your worked the night shift?

2. Are there any specific reasons that you are working the night shift?

3. Do you think there are any negative consequences to working the night shift?

4. Please describe any negative consequences that you have experienced.

5. In as much detail as possible, can you describe a time when you fell asleep driving home from work?

6. Do you have any ideas or suggestions as to what your hospital administrators could do to address this issue?

7. If you had the opportunity to speak to hospital administrators, what would you want them to know? 


\section{Appendix C}

Demographics

Dear

Please answer the following demographic questions and return to me via email.

Demographic Questions

1. Age?

2.

Years as a Registered Nurse?

3. Years on the Night Shift?

4.

Highest level of education?

5.

Type of Hospital you were employed in on the night shift?

Urban Rural

6.

Ethnicity?

7.

Marital Status? 
Appendix D

Informed Consent

\section{Informed Consent}

The University of Rhode Island

College of Nursing

White Hall

2 Heathman Road

Kingston, RI 02881

\section{Asleep Behind the Wheel: Experiences of Night Shift Nurses on the Commute Home}

\section{CONSENT FORM FOR RESEARCH}

You have been invited to take part in a research project described below. The researcher will explain the project to you in detail. You should feel free to ask questions. If you have more questions later, Shirley Sargent, RN the person mainly responsible for this study, 617-279-3119 will discuss them with you. You must be at least 18 years old to be in this research project.

Description of the project:

My name is Shirley Sargent, RN. I am currently working on a research study in nursing at the University of Rhode Island. My proposed study for my dissertation aims to explore the experiences of nurses who have fallen asleep behind the wheel on the commute home after a worked night shift. This study aims to answer the question: What is the experience of falling asleep behind the wheel on the drive home from a worked night shift? My hope is to illuminate the issue of night nurses and drowsy driving and shift work.

What will be done?

If you decide to take part in this study here is what will happen:

Anyone who chooses to take part will be requested to sign a consent form to partake in a 60 to 90 minute audio-taped interview which will be held at a time convenient to you and in a private meeting area or conference room.

Risks or discomfort:

The subject of discussion, driving drowsy and/or falling asleep behind the wheel, may be uncomfortable for you. If you experience any anxiety related to describing your experience with drowsy driving, including describing any accidents you may have had, you may discontinue the interview at any time.

Benefits of this study:

This researcher hopes that the study will benefit night shift nurses and improve standards in this area.

Confidentiality: 
Any information gathered from this study will remain confidential and anonymity will be maintained throughout the study. Your part in this study is confidential. None of the information will identify you by name. Any electronic data will be password protected and encrypted. Once the audiotapes have been transcribed, they will be kept in a locked file in a locked office available only to the researchers at the College of Nursing, White Hall, University of Rhode Island. Data will be stored for three years following completion of the study, and then it will be destroyed. Your part in this study is confidential within legal limits. The researchers and the University of Rhode Island will protect your privacy, unless they are required by law to report information to city, state or federal authorities, or to give information to a court of law. Otherwise, none of the information will identify you by name. Data entered into a computer database will have number identifiers only.

Decision to quit at any time:

Be advised that participation is voluntary and that you have the right to withdraw from the study at any time and any data obtained will be removed from the database. If you wish to quit, simply inform Shirley Sargent, 617-279-3119 of your decision. Rights and Complaints:

If you are not satisfied with the way this study is performed, you may discuss your complaints with Shirley Sargent, RN or with Marlene Dufault, Professor of Nursing in the College of Nursing at the University of Rhode Island 401-874-5307, anonymously, if you choose. In addition, if you have questions about your rights as a research participant, you may contact the office of the Vice President for Research, 70 Lower College Road, Suite 2, University of Rhode Island, Kingston, Rhode Island, telephone: (401) 874-4328.

You have read the Consent Form. Your questions have been answered. Your signature on this form means that you understand the information and you agree to participate in this study.

_ (Please check) I agree to let the researcher audiotape the interview.

Signature of Participant

Typed/printed Name
Signature of Researcher

Typed/printed name

Date

Date

Please sign both consent forms, keeping one for yourself. 
Appendix E

Institutional Review Board (IRB) Approval

\section{THE \\ UNIVERSITY \\ OF RHODE ISLAND \\ DTVISION OF RESEARCH \\ AND ECONOMTC \\ DEVELOPMENT}

OFFICE OF RESEARCH COMPLIANCE

70 Lower College Rlosd, turte 2, KIngeton, R1 02s81 USA

p: 401.874 .4328 t. $\mathbf{4 0 1 . 8 7 4 . 4 8 1 4}$ untodurecsarohtrobomplanoe

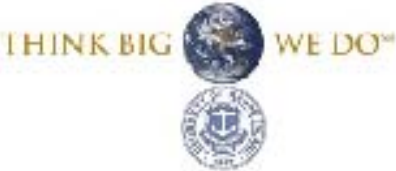

DATE:

May 18, 2012

TO:

Marlene Dufault, PhD, RN

FROM:

University of Rhode Island IRB

STUDY TITLE-

[334532-2] Asleep Behind the Wheel: Experiences of Night Shift Nurses on the Commute Home

IRB REFERENCE \#:

HU1112-130

SUBMISSION TYPE:

Revision

ACTION:

APPROVED

APPROVAL DATE:

EXPIRATION DATE:

May 18, 2012

REVIEW TYPE:

May 17, 2013

Expedited Review

REVIEW CATEGORY:

Expedited review category \# 7

Thank you for your submission of Revision materials for this research study. University of Rhode Island IRB has APPROVED your submission. This approval is based on an appropriate risk/benefit ratio and a study design wherein the risks have been minimized. All research must be conducted in accordance with this approved submission.

This submission has received Expedited Review based on the applicable federal regulation.

Please note that any revision to previously approved materials must be approved by this office prior to initiation. Please use the appropriate revision forms for this procedure.

All SERIOUS and UNEXPECTED adverse events must be reported to this office. Please use the appropriate adverse event forms for this procedure. All FDA and sponsor reporting requirements should also be followed.

Please report all NON-COMPLIANCE issues or COMPLAINTS regarding this study to this office.

Please note that all research records must be retained for a minimum of three years.

Based on the risks, this project requires Continuing Review by this office by May 17, 2013. Please use the appropriate renewal forms for this procedure.

If you have any questions, please contact us by email at compliance@ds.uri.edu. Please include your study title and reference number in all correspondence with this office.

Please remember that informed consent is a process beginning with a description of the study and insurance of participant understanding followed by a signed consent form. Informed consent must continue throughout the study via a dialogue between the researcher and research participant. Federal

$$
-1-
$$




\section{BIBLIOGRAPHY}

AAA Foundation. (2010). Asleep at the wheel.Retrieved from https://www.aaafoundation.org/sites/default/files/2010DrowsyDrivingReport 1-10-2013.

AAA Foundation. (2013). Traffic Safety Culture Index. Retrieved from https://www.aaafoundation.org/2012-traffic-safety-culture-index-motoristsadmit-driving-drowsy 1-10-2013.

AAA Foundation for Traffic Safety. (2004). Drunk or Drowsy? Retrieved from https://www.aaafoundation.org/sites/default/files/DrunkorDrowsy.pdf 3-1-2013.

Ackermann K; Revell VL; Lao O; Rombouts EJ; Skene DJ; Kayser M. (2012). Diurnal rhythms in blood cell populations and the effect of acute sleep deprivation in healthy young men. SLEEP, 35(7), 933-940.

Akerstadt, T. \& Wright, K. P. (2009). Sleep loss and fatigue in shift work and shift work disorder. Sleep Medicine Clinic, 4, 257-271.

Accreditation Council for Graduate Medical Education.(2011). Retrieved from http://www.acgme.org/acgmeweb/GraduateMedicalEducation/DutyHours.aspx 2-3-2013.

American Nurses Association. (2006). Assuring patient safety: Registered nurses' responsibility in all roles and settings to guard against working when fatigued. Retrieved from http://www.nursingworld.org/MainMenuCategories/PolicyAdvocacy/Positions-and-Resolutions/ANAPositionStatements/PositionStatements-Alphabetically/Copy-of-AssuringPatientSafety 3-15-2013 
Arendt, J. (2010). Shift work: coping with the biological clock. Occupational Medicine, 60, 10-20.

Bajraktarov S, Novotni A, Manusheva N, Nikovska DG, Miceva-Velickovska, E., Zdraveska N et al. (2011). Main effects of sleep disorders related to shift work-opportunities for preventive programs. The EPMA Journal, 2, 365-370.

Barnes-Farrell, J., Davies-Schrils, K., McGonagle, A., Walsh, B., Di Milia, L., Fischer, F., Hobbs, B., Kaliterna, L., \& Tepas, D. (2008). What aspects of shift work influence off-shift well-being of healthcare workers? Applied Ergonomics, 39, 589-596

Boyle, N., Tippin, J., Paul, A., \& Rizzo, M. (2008). Driver performance in the moments surrounding a microsleep. Transportation Research Part F, 11, 126136.

Brown, D.L., Feskanich, D., Sánchez, B.N., Rexrode, K.M., Schernhammer, E.S., Lisabeth, L.D., (2011). Rotating night shift work and the risk of ischemic stroke. American Journal of Epidemiology .Jun 1;169(11): 1370-1377.

Centers for Disease Control and Prevention. (2013). Drowsy driving-19 states and the District of Columbia 2009-2010. Morbidity and Mortality weekly Report 61[51 \& 52], 1033-1037. Retrieved from http://www.cdc.gov/mmwr/preview/mmwrhtml/mm6151a1.htm?s_cid=mm6151 a1_w 2-1-2013

CA Czeisler, C. A., Weitzman, E., Moore-Ede, M.C., Zimmerman, J. C., and Knauer R.S.,(1980). Human sleep: its duration and organization depend on its circadian phase. Science. 210 (4475), 1264-1267. 
Costa, G. (2003). Shift work and occupational medicine: an overview. Occupational Medicine (Oxford, England), 53, 83-88.

Dawson, D. \& Reid, K. (1997). Fatigue, alcohol and performance impairment. Nature, 388, 235.

Dembe A.E. (2009). Ethical issues relating to the health effects of long working hours. Journal of Business Ethics, 84, 195-208.

Dement, W. (1997). What All Undergraduates Should Know About How Their Sleeping Lives Affect Their Waking Lives. Retrieved from http://www.stanford.edu/ dement/sleepless.html 1-2-2013.

Dey, I. (1993). Qualitative data analysis: a user friendly guide for social scientists. London: Routledge.

Diagnostic and Statistical Manual of Mental Disorders (2013). Retrieved from http://en.wikipedia.org/wiki/Diagnostic and Statistical Manual of Mental Disorders 1-13-2013

Domrose, C. ,(2006). Good night staff - taking care of ourselves. Retrieved from http://news.nurse.com/apps/pbcs.dll/article?AID=2006601160308 2-16-2013.

Dorrian, J., Lamond, N. \& Dawson, D. (2000). The ability to self-monitor performance when fatigued. Journal of Sleep Research, 9, 137-144.

Dorrian, J., Lamond, N., van den Heuvel, C., Pincombe, J., Rogers, A.E., Dawson, D.A.,(2006). A pilot study of the safety implications of Australian nurses' sleep and work hours. Chronobiology International, 23(6), 1149-1163. 
Dorrian, J., Tolley, C., Lamond, N., van den Heuvel ,C. , Pincombe, J., Rogers , A.E., Drew, D., (2008). Sleep and errors in a group of Australian hospital nurses at work and during the commute.Applied Ergonomics Sep, 39(5), 605-613.

Elo, S. \& Kyngas, H. (2008). The qualitative content analysis process. Journal of Advanced Nursing, 62, 107-115.

Falleti, M. G., Maruff, P., Collie, A., Darby, D. G., \& .McStephen, M. (2003). Qualitative similarities in cognitive impairment associated with 24h of sustained wakefulness and a blood alcohol concentration of 0.05\%. Journal of Sleep Research, 12, 265-274.

Fallis, W. M., McMillan, D. E., \& Edwards, M. P. (2011). Napping during night shift: practices, preferences, and perceptions of critical care and emergency department nurses. Critical Care Nurse, 31, e1-11.

Feskanich, D., Hankinson, S. E., Schernhammer, E. S., (2009). Nightshift work and fracture risks:the nurses' health study. Osteoporosis International, 20(4), 537542.

Flight Duty Times. (2013). Pilot asleep in the cockpit. Retrieved from http://www.flightdutytimes.eu/ 1-4-2013.

Folkard, S., Lombardi, D. A., Tucker, P.T., (2005). Shiftwork: safety, sleepiness and sleep. Industrial Health, 43(20), 23.

Gamble K. L., et al. (2011). Shift Work in Nurses: Contribution of Phenotypes and Genotypes to Adaptation. PLoS ONE . http://www.plosone.org/article/info\%3Adoi\%2F10.1371\%2Fjournal.pone.001 8395 12-24-2012. 
Geiger-Brown, J. \& Trinkoff, A. M. (2010). Is it time to pull the plug on 12-hour shifts? Journal of Nursing Administration, 40, 100-102.

Gold,D. R., Rogacz,S., Bock, N., Tosteson, T. D., Baum, T. M., Speizer, F. E., Czeisler, C. A., ( 1992). Rotating shift work, sleep, and accidents related to sleepiness in hospital nurses. American Journal of Public Health, 82, 10111014.

Goleman, D. (1979). Consciousness: The brain, states of awareness, \& alternate realities. New York: Irvington Publishers.

Graneheim, U. H. \& Lundman, B. (2004). Qualitative content analysis in nursing research: concepts, procedures and measures to achieve trustworthiness . Nurse Education Today, 24, 105-112.

Guest, G., Bunce, A., \& Johnson, L. (2006). How many interviews are enough?: An experiment with data saturation and variability. Field Methods, 18, 59-82.

Horne, J. \& Reyner, L. A. (1999). Vehicle accidents related to sleep: a review. Occupational and Environmental Medicine, 56, 289-294.

Hughes, R. \& Stone, P. (2004). The perils of shiftwork: Evening shift, night shift and rotating shifts: Are they for you? American Journal of Nursing, 104, 60-63.

Institute of Medicine. (2003). Keeping patients safe: Transforming the work environment of Nurses. http://www.iom.edu/Reports/2003/Keeping-PatientsSafe-Transforming-the-Work-Environment-of-Nurses.asp. 1-4-2013.

Jeyaraj, D., Haldar, S. M., Wan, X., McCauley, M. D., Ripperger, J. A., Hu, K. et al. (2012). Circadian rhythms govern cardiac repolarization and arrhythmogenesis. Nature, 483, 96-99. 
Kawachi, I., Graham, C. A., Stampfer, M. J., Willett, W. C., Mandon, J. E., Speizer, F. E. et al. (1995). Prospective study of shift work and risk of coronary heart disease in women. Circulation, 92, 178-182.

Knutsson, A. (2003). Health disorders of shift workers. Occupational Medicine, 53, 103-108.

Kuhar, S., (2013). Drowsy driving prevention. http://www.safeny.ny.gov/drowndx.htm 3-2-2013.

Lamond, N., Dawson, D., (1999) Quantifying the performance impairment associated with fatigue. Journal of Sleep Research, (8), 255-262.

Lie, J.A., et al., (2011). Night work and breast cancer risk among Norwegian nurses: assessment by different exposure metrics. American Journal of Epidemiology, 173, 1272-1279.

Lincoln, Y.S., \& Guba, E. G.(1985). Naturalistic inquiry. Newbury Park, CA: Sage Publications

Lombard, M., Snyder-Duch, J., \& Bracken, C. (2005). Practical resources for assessing and reporting intercoder reliability in content analysis research projects. http://matthewlombard.com/reliability/ 1-18-13.

Maxwell, J. A. (2006). Qualitative research design: an interactive approach. Thousand Oaks, CA: Sage

McCann, K. (2008). Nurses working overnight support the need for a restorative nap during the night shift. http://www.aasmnet.org/articles.aspx?id=876 2-10-13. 
McCartt A.T, Ribner S.A, Pack A.I., \& Hammer, M. C. (1996). The scope and nature of the drowsy driving problem in New York State. Accident Analysis and Prevention, 28, 511-517.

Megdala, S. P., Kroenke, C. H., Laden, F., Pukkala, E., \& Schernhammer, S. (2005). Night work and breast cancer risk: A systematic review and meta-analysis. European Journal of Cancer, 41, 2023-2032.

National Highway Traffic Safety Administration \& National Center on Sleep Disorders Research. (1999). The NHTSA \& NCSDR program to combat drowsy driving. 1-4-2013.

National Institutes of Neurological Disorders and Stroke. (2007). Brain basics:understanding sleep. National Institutes of Health . http://www.ninds.nih.gov/disorders/brain_basics/understanding_sleep.htm 22-2013.

National Sleep Foundation (2012). FAA Issues Final Rule on Pilot Fatigue. Retrieved from http://www.sleepfoundation.org/alert/faa-issues-final-rulepilot-fatigue. 4-18-2012

Neergaard, M., Olesen, F., Andersen, R., \& Sondergaard, J. (2009). Qualitative description - the poor cousin of health research? BMC Medical Research Methodology, 9, 52.

Nelson, T., Isaac, N., \& Graham, J. (1998). Development and Testing of Countermeasures for Fatigue Related Highway Crashes:ocus Group Discussions with Young Males, Shift Workers, and Shift Work Supervisors. 
Harvard School of Public Health, Section II.

http://www.nhtsa.gov/people/injury/drowsy_driving1/listening/title.htm 2-16-2013.

New York State Partnership Against Drowsy Driving (NYPDD) Retrieved from: http://www.safeny.ny.gov/drow-ndx.htm 3-2-2013 Ref Type: Online Source

Newton, N. (2010). The use of semi-structured in qualitiative research: strengths and weaknesses. http://www.academia.edu/1561689/The_use_of_semistructured_interviews_in_qualitative_research_strengths_and_weaknesses 127-2013.

Novak, R. D. \& Auvil-Novak, S. E. (1996). Focus group evaluation of night nurse shiftwork difficulties and coping strategies. Chronobiology International, 13, 457-463.

Nuendorf, K. (2002). The content analysis guidebook. Thousand Oaks, CA: Sage Publications.

Owens, J. A. (2007). Sleep loss and fatigue in healthcare professionals. Journal of Perinatal and Neonatal Nursing, 2(2), 92-100.

Page, A. (Ed.).(2004). Keeping patients safe: Transforming the work environment of nurses. http://www.nap.edu/openbook.php?record 1-15-2013

Philip, P. \& Mitler, M. (2000). Sleepiness at the wheel: symptom or behavior. Sleep, 15, S-199-S-121.

Pietroiusti, A., Somma, G., Coppeta, L., Iavicoli, L., Bergamaschi, I., Magrini, A., (2010). Incidence of metabolic syndrome among night shift healthcare workers. Occupational and Environmental Medicine, (67)1, 54-57. 
Polit, D. F. \& Tatano-Beck, C. (2004). Research, principles and methods, (7th ed.). Philadelphia, PA: Lippincott, Williams \& Wilkins.

Price, M. (2011). The risks of night work. Retrieved from http://www.apa.org/monitor/2011/01/night-work.aspx 12-27-2012

Rogers, N. L., \& Dinges, D. F. (2002) Shiftwork, circadian disruption and consequences. Primary Psychiatry, 9(8), 50-56

Rogers, A. E., Hwang, W. T., Scott, L. D., Aiken, L. H., \& Dinges, D. F. (2004). The working hours of hospital staff nurses and patient safety. Health Affairs, 23, 202-212.

Rubin, H. \& Rubin, I., (1995). Qualitative interviewing: The art of hearing data.Thousand Oaks, CA: Sage

Rubin, H. J. \& Rubin, I. S. (2005). Qualitative interviewing-the art of hearing data. (2nd ed.) Thousand Oaks, CA: Sage Publications.

Sagberg, F., Jackson, P., Kruger, H., \& Williams, A. (2004). Fatigue, sleepiness and reduced alertness as risk factors in driving. In IMMORTAL European Commission.

Salisbury, D. (2011). Sleep strategy used by night nurses throws off their circadian clocks. Research News at Vanderbilt . Retrieved from http://news.vanderbilt.edu/2011/04/nurse-sleep-circadian-clocks/ 12-22-2012.

Sandelowski, M. (2000). Whatever happened to qualitative description? Research in Nursing and Health, 23, 334-340.

Scheer, F. A., Hilton, M.F., Mantzoros,C.S., Shea, S.A., (2009). Adverse metabolic and cardiovascular consequences of circadian misalignment. Proceedings of 
the National Academy of Sciences of the United States of America (PNAS).106(11):4453-4458.

Schernhammer, E.S., Laden, F., Speizer, F.E., Willett, W.C>, Hunter, D.J., Kawachi, I., Fucjhs, C.S., Colditz, G.A., (2003). Journal of the National Cancer Institute. 95 (11), 825-828.

Scott L. D.,Hwang, W., Rogers, A. E., Nysse, T. Dean, .G.E., Dinges, D.F.( 2007). The Relationship between Nurse Work Schedules, Sleep Duration, and Drowsy Driving. Sleep, 30(12), 1801-1807.

Schmidt, C. e. al. (2009). Homeostatic sleep pressure and responses to sustained attention in the suprachiasmatic area. Science, 324, 516-519.

Scott, L.D., Hwang, W.T., Rogers, A.E., Nysse, T., Dean, G.E., Dinges, D.F. (2007). The relationship between nurse work schedules, sleep duration, and drowsy driving. Sleep, 30(12), 1801-1807.

Seidman, I. E. (1991). Interviewing as qualitative research: A guide for researchers in education and the social sciences. New York: Teachers College Press.

Smith-Coggins, R., Howard, S., Mac, D., Wang, C., Kwan, S. \& Rosekind, M. (2006). Improving alertness and performance in emergency department physicians and nurses: The use of planned naps. Annals of Emergency Medicine, 48(5), 596604.

Stokowski, L. A. (2004). Wake-up call for nurses: Sleep loss, safety, and health. 7th Annual Neonatal Advanced Practice Nursing. http://www.medscape.org/viewarticle/481189 2-18-13 
Straif, K. (2007). IARC monographs programme finds cancer hazards associated with shiftwork, painting and firefighting (Rep. No. Press Release \#180). http://www.iarc.fr/en/media-centre/pr/2007/pr180.html 1-10-2013.

Su,T.C., Lin, L.Y., Baker ,D., Schnall ,P.L., Chen ,M.F., Hwang, W.C., Chen, C.F., Wang ,J.D., (2008). Elevated blood pressure, decreased heart rate variability and incomplete blood pressure recovery after a 12-hour night shift work. Journal of Occupational Health, 50(5), 380-386.

Sullivan-Bolyai, S., Bova, C., \& Harper, D. (2005) Developing and refining interventions in persons with health disparities: The use of qualitative description. Nursing Outlook, 53, 127-133.

Surani,S., Subramanian, S., Babbarn, H., Murphy, J., Aquillar, R.,(2008). Sleepiness in critical care nurses: Results of a pilot study. Journal of Hospital Medicine, (3)3, 200-205.

Swinhart, D.J., (2007)The 24-Hour Shift: Impact on Health and Safety. Retrieved from $h t t p: / / w w w . f i r e e n g i n e e r i n g . c o m / a r t i c l e s / p r i n t / v o l u m e-160 / i s s u e-$ 5/departments/fire-service-ems/the-24-hour-shift-imp 12-22-2012 The Joint Commission (2003). Care Delivery and the Environment of Care: A Teamwork Approach. Oak Brook Terrace, IL: Joint Commission Resources.

The Joint Commission. (2011). Health care worker fatigue and patient safety. The Joint Commission Sentinel Event Alert Issue 48. Retrieved from http://www.jointcommission.org/sea_issue_48/.2-1-2013.

Walcutt, D. (2009). Stages of sleep. PsychCentral Retrieved from http://psychcentral.com/lib/2009/stages-of-sleep/. 1-10-2013. 
Webb, J. J., ( 2011). Nursing research and evidence-based practice. In B. Cherry \& S. Jacob (eds). Contemporary nursing : issues, trends, \& management. (121). St. Louis, Mo. : Elsevier/Mosby

West, S. H.,(2007). New graduate nurses adaptation to shift work:can we help? Collegian, 14 (1), 23-30

Wever, R.A., (1985). In S. Folkard, \& T. H. Monk (Eds.), Man in temporal isloation: basic principles of the circadian system., (p.15-28). Chichester: John Wiley and Sons, Inc.

World Health Organization (2010). White paper for safe roads in 2050 :achieving zero work-related road deaths. Retrieved from: http://www.who.int/roadsafety/ 1-11-2013. 